\title{
Sinopsis de los mamíferos silvestres del estado de Guanajuato, México, y comentarios sobre su conservación
}

Óscar Sánchez ${ }^{1}$

Introduction. Alfred Dugès (1826-1910) began the formal study of wild mammals in the state of Guanajuato, Mexico. After his death the subject remained virtually forgotten for almost a hundred years. In the early years of the XXI century several authors began a period of revision of this state fauna based on recent field surveys, museum specimens and previously unnoticed literature.

Objectives. The objectives of the present contribution were: to integrate a synopsis of the mammalian fauna of Guanajuato, documenting details for species and subspecies, recognizing proportions of its components at the family level; diagnose the current state coverage of records at the municipality level; outline general biogeographic affinities of the mammal fauna; develop a general conservation view with emphasis on endangered species and protected areas (but without losing sight of other species, spaces and policy instruments), and indicate pending aspects.

Methodology. Results of previous literature reviews and museum specimen searches served to summarize mammal species richness, general state distribution and conservation status of taxa. Faunal affinities were outlined considering mammal species whose distribution is clearly associated with large physiographic-biogeographic regions converging in Guanajuato. Information on species at risk, protected areas, priority species, species management units and trade regulations, was gathered and collated to build an integrated conservation diagnostic. Lack of information on other conservation aspects was also addressed and main gaps were identified.

Results. Ninety three species of 20 mammal families are known from Guanajuato, mainly Rodentia, Chiroptera and Carnivora. Records were found for 30 of 46 municipalities; but are still unrepresentative. Only 25 species have been recorded in more than five municipalities (Figure 4). The mammal fauna has affinity with the Mexican Plateau, with the slopes of the Gulf of Mexico and of the Pacific, and the Neovolcanic Belt (Figure 5). Most of the territory in Guanajuato is considerably disturbed (Figure 6); main conservation strongholds for species at risk are related to protected areas.

Discussion and Conclusions. The 93 recorded species were catalogued with data on subspecies, general state distribution, and comments on taxonomy and conservation status. Guanajuato still needs systematic sampling; current records are not yet representative of the territory. This mammal fauna is a complex with different biogeographical components, which should guide any conservation strategy. Alteration of territory calls for effective conservation within protected natural areas (PNA), particularly for species at risk, but some PNAs do not have a validated mammal inventory. Management units (UMA) are scarce and aim at fostering a few species of economic interest; these units need to reorient their overall support for conservation of native biota. Some species are officially considered as priority ones, which can induce/enhance conservation in Guanajuato. Besides deepening the knowledge of species per se, several conservation aspects are pending, as examples: generate management plans for species at risk in PNAs and outside them, check the operation

19Alhelí 613-A, Las Flores, San Lorenzo Tepaltitlán, 50018, Estado de México, México. E-mail: teotenango@yahoo.com 
of UMA with emphasis on the subspecies of whitetail deer that have been introduced and managed, combat exotic and invasive species in the wild (this includes reducing extensive grazing), and characterize the social perception about conservation of mammals and their natural habitat.

Key words: Conservation, diversity, geography, Guanajuato, mammals, Mexico, priorities, richness, taxonomy.

Alfredo Dugès (1826-1910) inició el estudio formal de los mamíferos silvestres del estado de Guanajuato, México. Luego de su muerte este tema permaneció prácticamente olvidado por casi cien años. Al inicio del Siglo XXI varios autores comenzaron una etapa de revisión sobre distintos componentes de esta fauna estatal (Sánchez y MagañaCota 2008, Sánchez et al. 2009, Sánchez et al. 2012, Magaña-Cota et al. 2012, Sánchez et al. 2014,) con base tanto en resultados de exploraciones de campo recientes como en ejemplares de museo y literatura previamente inadvertida. Los objetivos de la presente contribución fueron integrar una sinopsis de la mastofauna de Guanajuato, documentada a detalle respecto a especies y subespecies; reconocer las proporciones de sus componentes a nivel de familias; diagnosticar la cobertura actual de registros a escala de municipios; trazar las afinidades biogeográficas generales de la mastofauna; elaborar una perspectiva integrada de conservación con énfasis en las especies en riesgo y áreas naturales protegidas (pero sin perder de vista al resto de las especies, otros espacios e instrumentos de política pública), e indicar aspectos pendientes de estudio.

Se retomaron resultados de revisiones previas de literatura y registros de ejemplares en museos para resumir la riqueza mastofaunística del estado, la distribución general y estatus de conservación de los taxones. Se consideró la vinculación de ciertas especies de mamíferos con las grandes regiones fisiográfico-biogeográficas de México que convergen en Guanajuato, para esbozar las afinidades de la mastofauna. Se reunió y comparó información sobre especies en riesgo, áreas naturales protegidas, especies prioritarias, especies en unidades de manejo y regulaciones comerciales aplicables, para construir un diagnóstico integrado. También se identificaron aspectos pendientes de atención respecto a la conservación de mamíferos silvestres. Se conocen de Guanajuato 93 especies de 20 familias, principalmente Rodentia, Chiroptera y Carnivora. Existen registros para 30 de 46 municipios; aún son poco representativos. Sólo 25 especies se han registrado en más de cinco municipios. La mastofauna tiene afinidad con la Altiplanicie Mexicana, con la vertiente del Golfo de México, con la vertiente del Pacífico y con el Eje Neovolcánico. El entorno natural de Guanajuato está muy alterado; la base de conservación para especies en riesgo se relaciona con las áreas naturales protegidas. Las 93 especies conocidas se han compendiado, con datos sobre subespecies y su distribución estatal general, anotaciones taxonómicas y de estatus de conservación. Guanajuato aún necesita muestreo sistemático; los registros actuales aún no son representativos del territorio. La mastofauna es un complejo con distintos componentes biogeográficos, lo que debe orientar cualquier estrategia de conservación. La alteración del territorio reclama eficacia en la conservación dentro de áreas naturales protegidas (ANP), particularmente para las especies en riesgo; varias ANP aún no cuentan con inventario validado de mamíferos. Las unidades de manejo (UMA) son escasas y se orientan una cuantas especies aprovechables; necesitan reorientar su apoyo integral 
a la conservación de la biota nativa. En Guanajuato existen especies oficialmente consideradas como prioritarias, que pueden inducir/potenciar la conservación. Además de profundizar el conocimiento sobre las especies varios aspectos de conservación están pendientes, como ejemplos: generar planes de manejo para especies en riesgo en ANP y fuera de ellas, verificar el funcionamiento de UMA incluyendo las subespecies de venado cola blanca que han introducido y manejan, combatir especies exóticas e invasoras en libertad (incluyendo disminuir el pastoreo extensivo), y tipificar de la percepción social sobre la conservación de mamíferos y sus hábitat naturales.

Palabras clave: Conservación, diversidad, geografía, Guanajuato, mamíferos, México, prioridades, riqueza, taxonomía.

\section{Introducción}

El estudio de los mamíferos silvestres del estado de Guanajuato se inició en el Siglo XIX con las publicaciones de Alfredo Dugès (1826-1910); entre sus contribuciones de síntesis destacan las de 1870, 1890 y 1895. Desde entonces y hasta la mitad del Siglo XX hubo un visible hiato en el que se produjeron sólo trabajos esporádicos; más adelante diversos autores produjeron publicaciones en las que se mencionan mamíferos silvestres del estado, aunque no expresamente con un enfoque faunístico sobre la entidad. En los últimos años se han elaborado revisiones históricas y actualizaciones para ciertos grupos de mamíferos de Guanajuato: murciélagos (Sánchez y Magaña-Cota 2008 y Sánchez et al. 2009); roedores (Magaña-Cota et al. 2012). También se han efectuado nuevas exploraciones en la Sierra de los Agustinos (Apátiga et al. 2008) y en el noreste del estado (Elizalde-Arellano et al. 2010), y se han agregado registros puntuales para algunas especies (Iglesias et al. 2008; Magaña-Cota et al. 2010; Sánchez-Cordero et al. 2011; Charre-Medellín et al. 2012a y 2012b, y Cecaira-Ricoy et al. 2012). Recientemente se produjo una primera síntesis actualizada sobre la mastofauna estatal (Sánchez et al. 2012) y también una revisión sobre los mamíferos no voladores (Sánchez et al. 2014).

La síntesis de 2012, para actualizar la mastofauna estatal, se basó en la literatura publicada hasta 2010 y en diversos registros de ejemplares en museos de México y los Estados Unidos de Norteamérica. Por su naturaleza general, ese trabajo se limitó al nivel taxonómico de especie y no hizo referencia a la distribución geográfica conocida de éstas en el estado. La revisión de más publicaciones, la aparición de nuevos registros estatales de especies, de un resumen sobre roedores de Guanajuato (Magaña-Cota et al. 2012), de una revisión histórica y síntesis general sobre los mamíferos no voladores (Sánchez et al. 2014) y de varias revisiones de grupos taxonómicos, han estimulado una sinopsis del conocimiento sobre los mamíferos del estado con comentarios a mayor detalle.

En la presente contribución se buscó generar una guía taxonómica más completa sobre la mastofauna de Guanajuato con base en la información hasta 2014, considerando ahora las subespecies relacionadas con el territorio estatal y registros que las sustentan. También se intentó describir la composición de la mastofauna por taxones mayores, ofrecer una estimación gruesa de la cobertura actual del muestreo del estado, por el momento a la escala de municipios, y hasta donde la información lo permitió se trató de identificar las afinidades biogeográficas generales de esta fauna estatal. También se 
concentró la información existente sobre la situación de riesgo de los taxones presentes en el estado, según referencias de escala global y nacional. Para las especies en riesgo se ubicaron las relaciones de los registros existentes con áreas naturales protegidas del estado, con el propósito de orientar el inicio de prospecciones de sus poblaciones en esas áreas y la toma de decisiones sobre medidas de conservación adecuadas.

Los resultados de esta sinopsis permitieron identificar algunos vacíos de información, prioridades de investigación y de conservación de los mamíferos en Guanajuato.

Los insumos de esta contribución son listados de especies de mamíferos, entre ellos las síntesis históricas y revisiones faunísticas de Sánchez y Magaña-Cota (2008); Sánchez et al. (2009); Magaña-Cota et al. (2012) y Sánchez et al. (2012), así como diversa literatura sobre grupos particulares de especies e información de ejemplares presentes en distintos museos (Sánchez et al. 2014). Con esos datos se produjo una lista unificada de las especies de mamíferos de Guanajuato.

Para la secuencia de presentación de los taxones se tomó como base la publicación de Ceballos y Arroyo-Cabrales (2012), que incluye modificaciones de la nomenclatura efectuadas en la década reciente. No obstante, en la presente contribución se mantienen posiciones diferentes en algunos aspectos: Ceballos y Arroyo-Cabrales (2012) hacen referencia en su lista a la familia Muridae de los roedores y dentro de ella, a una sola subfamilia (Neotominae); aquí se considera válida la familia Cricetidae con base en evidencia molecular y en la filogenia de los Muroidea reconstruida por Steppan et al. (2004), en la que además se validan las subfamilias Arvicolinae, Tylomyinae, Neotominae y Sigmodontinae (de las cuales las dos últimas están representadas en Guanajuato). Por otra parte, la lista en Ceballos y Arroyo-Cabrales (2012) considera válida la familia de quirópteros Antrozoidae siguiendo a Simmons (1998). Sin embargo, evidencia más reciente (Hoofer y Van Den Bussche 2001, Hoofer y Van Den Bussche 2003, y Roehrs et al. 2010) indica que se justifica considerarla una subfamilia dentro de Vespertilionidae (Antrozoinae); en la edición más reciente de Wilson y Reeder (2005) Simmons ya la recoloca como Antrozoinae. Por otra parte, Wilson y Reeder (2005) reconocen varias tribus dentro de la subfamilia Vespertilioninae, posición que aquí se sigue al mencionar aquellas a las que corresponden las especies presentes en Guanajuato (Eptesicini, Lasiurini, Nycticeiini, Pipistrellini y Plecotini).

En relación con los nombres de los géneros de murciélagos Baeodon y Parastrellus se adopta la postura tomada por Ramírez-Pulido et al. (2005) reconociéndolos como válidos. En cuanto a los murciélagos del género Sturnira, en este trabajo se considera la nomenclatura propuesta por Velazco y Patterson (2013), quienes en su revisión filogeográfica del género elevaron S. lilium parvidens al estatus de especie (actualmente queda como $S$. parvidens) y también refrendan la reubicación de S. ludovici hondurensis en la jerarquía de especie ( $S$. hondurensis) hecha por ludica (2000).

Tomando la propuesta de Helgen et al. (2009), en la lista se emplean nombres genéricos separados para las ardillas Ictidomys, Otospermophilus y Xerospermophilus, las cuales anteriormente estuvieron subsumidas en el género Spermophilus. Para las tuzas del género Cratogeomys se siguió la opinión de Hafner et al. (2004) en la cual se establece que $C$. tylorhinus y $C$. zinseri son sinónimos de $C$. fumosus. En el caso 
de las tuzas menores (Thomomys) se consultó el estudio de Álvarez-Castañeda (2010) que indica que el complejo Thomomys bottae-umbrinus en realidad podría incluir más de dos especies. Respecto al género Oryzomys se consideró el trabajo de Carleton y Arroyo-Cabrales (2009), que considera válida la especie O. albiventer.

En el caso de la familia Heteromyidae se adopta provisionalmente la postura de Hafner et al. (2007), fundamentada en evidencia del análisis de genes mitocondriales, respecto a que el género Liomys puede considerarse sinónimo de Heteromys; esto presentaría un esquema filético más congruente, al eliminar una situación de parafilia anteriormente implicada entre ambos géneros. Asimismo, se consideró una revisión de la especie antes conocida como Dipodomys phillipsii (Gray 1841), de la cual la subespecie D. p. ornatus ha sido reconocida como especie distinta (D. ornatus; Fernández et al. 2012). Coincidiendo con Ceballos y Arroyo-Cabrales (2012) aquí se conserva el nombre del jaguarundi como Herpailurus yagouaroundi, a pesar de que (Wilson y Reeder 2005) lo incluyen en el género Puma considerando el resultado de estudios moleculares como los de Mattern y McLennan (2000), y de que en Sánchez et al. (2014) se refirió como $P$. yagouaroundi. Este cambio obedece a que publicaciones muy recientes reconocen la monofilia de Puma y Herpailurus, con Acinonyx como un clado vecino, pero continúan utilizando Herpailurus (Segura et al. 2013): la controversia aún no puede considerarse resuelta, por lo que provisionalmente aquí se decidió retomar una posición más conservadora respecto a la nomenclatura.

Las autoridades taxonómicas asociadas con cada nombre de especie y subespecie se revisaron cotejándolas conforme a Wilson y Reeder (2005) y otras publicaciones que las mencionan (Ramírez-Pulido et al. 2005, Ceballos et al. 2005, Ceballos y Arroyo-Cabrales, 2012). Se sugiere a los lectores acudir a la literatura taxonómica especializada referida por Wilson y Reeder (2005) y a publicaciones más recientes aquí citadas, para acceder a las referencias de publicación original de los nombres específicos y subespecíficos que se utilizan.

Se efectuó un sencillo análisis por taxones mayores para conocer la composición de esta fauna estatal. Al revisar los registros de mamíferos para Guanajuato presentes en la literatura y en bases de datos de museos se obtuvieron un número considerable de localidades, las cuales se hallan en proceso de cartografía para empezar a reconocer los patrones de distribución de las distintas especies en la entidad; por ello en esta primera oportunidad se han referido sólo como presencia por municipio, con lo cual se pretende por ahora ofrecer un panorama de la actual cobertura general de muestreo del estado. Para cada especie, o subespecie cuando fue el caso, se menciona su estado de riesgo estimado; a escala global conforme la Lista Roja de la (IUCN 2012, versión 3.1 de las categorías de riesgo) y a escala nacional con la lista de la NOM059-SEMARNAT-2010 (SEMARNAT 2010). Respecto a las regulaciones de comercio internacional, las disposiciones de la Convención sobre el Comercio Internacional de Especies Amenazadas de Fauna y Flora Silvestres (CITES) sólo se aplican a ciertas especies presentes en Guanajuato; en esos casos se mencionan conforme a los Apéndices CITES vigentes a partir del 25 de septiembre de 2012.

Aunque el propósito principal de la presente contribución es proveer una sinopsis taxonómica comentada y dejar constancia de la situación actual del conocimiento sobre los mamíferos silvestres de la entidad, los casos de taxones en categorías de 
riesgo global, nacional o ambos, resultan una prioridad para el estado. Por ello, en una primera aproximación gruesa se relacionaron los registros existentes con la ubicación de áreas naturales protegidas de Guanajuato (federales y estatales) con las que están efectivamente vinculados por su ubicación o a las cuales se hallan más cercanos, considerando un buffer de no más de $10 \mathrm{~km}$ en torno a un registro dado respecto al límite de un área natural protegida, de acuerdo con el mapa general elaborado por el Instituto de Ecología del Estado de Guanajuato (2013). Por el momento solo se ha buscado identificar las áreas protegidas relacionadas con esos registros de especies en riesgo, pues la información disponible en el momento no resulta suficiente para abordar análisis más sofisticados.

Lista taxonómica integrada de los mamíferos silvestres del estado de Guanajuato. En una publicación anterior sobre la mastofauna de Guanajuato (Sánchez et al. 2012) se hizo un recuento de 87 especies de mamíferos. Una revisión reciente respecto a los mamíferos no voladores del estado (Sánchez et al. 2014) permitió rescatar registros de otros taxones existentes en la literatura, con lo que por una parte Cratogeomys tylorhinus y $C$. zinseri quedaron incluidas en la actual $C$. fumosus y por otra se agregaron Tlacuatzin canescens, Glaucomys volans, Xerospermophilus spilosoma, Peromyscus hylocetes, Lontra longicaudis, Diphylla ecaudata y Macrotus waterhousii. En suma, hasta el momento se han registrado en Guanajuato 93 especies de mamíferos silvestres.

En la lista que se provee aquí, las especies aparecen en orden alfabético dentro de cada familia. La lista menciona las subespecies particulares de mamíferos silvestres vinculadas con el territorio de Guanajuato. Para cada taxón se mencionan solamente los municipios donde se ha registrado; los nombres geográficos se refieren a éstos y no necesariamente a ciudades particulares homónimas. Para la mayoría de los registros se indican directamente los museos donde se encuentran y sus números de catálogo.

Para otros se indican las publicaciones que los han registrado, de las que la mayoría señalan los números de catálogo de los ejemplares o fichas fotográficas sistematizadas albergados en museos. Debido a que algunos ejemplares conservados en ENCB-IPN y MLZ-OC se encuentran en proceso de revisión curatorial, por ahora no se proveen números de catálogo. Los acrónimos de los museos donde se encuentran los ejemplares mencionados se presentan en el Apéndice I.

Respecto al estado de riesgo (IUCN, NOM-059-SEMARNAT-2010) o de regulación comercial (CITES) sólo se incluye información: (a) cuando la especie en su conjunto es aludida como tal, y (b) cuando es necesario aclarar situaciones particulares para Guanajuato si la NOM o los Apéndices CITES se refieren a determinadas subespecies.

La descripción del estatus de conservación de los taxones se ha reducido a su mínima extensión para simplificar la lectura.

También se indican aquellas especies de Guanajuato contenidas en el Acuerdo por el que se da a conocer la lista de especies y poblaciones prioritarias para la conservación en México (SEMARNAT 2014: aquí abreviado como SEMARNAT-E P-2014), instrumento que enlista especies que ofrecen oportunidades para dar mayor alcance a los esfuerzos de conservación, al permitir extender los beneficios a otras con las que coexisten.

Finalmente, las especies marcadas con asterisco $(*)$ se consideran extirpadas de Guanajuato en tiempos históricos, probablemente entre la conquista española y el Siglo XIX. 


\section{ORDEN DIDELPHIMORPHIA \\ Familia Didelphidae \\ Subfamilia Didelphinae}

1. Didelphis virginiana Kerr, 1792. Subespecie en Guanajuato: D. virginiana californica Bennett, 1833. Existen registros para los municipios de Celaya (USNM 78428 y 78481), Dolores Hidalgo (CNMA 4158), Santa Catarina (CNMA 21866) y San Miguel de Allende (CNMA 4159), Guanajuato (MADUG-MA355, 287, 289, 62, 18, 70, 205, 286 y 558; USNM 19697, colectado por A. Dugès), León (ENCB-IPN), San Luis de la Paz (ENCBIPN) y Victoria (ENCB-IPN). Apátiga et al. (2008) la mencionan para el municipio de Acámbaro. Lozoya Gloria y Uriarte Garzón (2012) para Irapuato, e Iglesias et al. (2012) para Xichú. Estado de conservación: Lista Roja IUCN, especie de menor preocupación (Least Concern).

2. Tlacuatzin canescens (J. A. Allen, 1893). Subespecie en Guanajuato: T. canescens canescens (J. A. Allen, 1893). Dugès (1890) registró este taxón para el estado, aunque no mencionó una localidad particular. Existen registros publicados del extremo norte de Michoacán, exactamente en un sitio limítrofe con Guanajuato (Núñez-Garduño, 2005) por lo que se ha considerado que este taxón ocupa al menos el extremo sur-suroeste del estado (Sánchez et al. 2014). Estado de conservación: Lista Roja IUCN, especie de menor preocupación (Least Concern).

\section{ORDEN CINGULATA \\ Familia Dasypodidae \\ Subfamilia Dasypodinae}

3. Dasypus novemcinctus Linnaeus, 1758. Subespecie en Guanajuato: D. novemcinctus mexicanus Peters, 1864. Se conocen ejemplares de los municipios de Celaya (MADUGMA 67, 69 y 319), Cuerámaro (MADUG-MA 280) y Salamanca (MADUG-MA 191) y de Guanajuato (USNM A16464, colectado por A. Dugès en 1881). Apátiga et al. (2008) lo reportaron para Acámbaro, Charre-Medellín et al. (2012b) para Victoria, e Iglesias et al. (2012) para Xichú. Estado de conservación: Lista Roja IUCN, especie de menor preocupación (Least Concern).

\section{ORDEN LAGOMORPHA \\ Familia Leporidae \\ Subfamilia Leporinae}

4. Lepus californicus Gray, 1837. Subespecie en Guanajuato: Lepus californicus asellus Miller, 1899. Se conoce de los municipios de Tierra Blanca (CNMA 21767) e Irapuato (Uriarte Garzón y Lozoya-Gloria 2009), de San Luis de la Paz (CNMA 29037; ENCB-IPN) y San Miguel de Allende (UMMZ 92232; otro ejemplar, 92231, sólo indica "Guanajuato"). Estado de conservación: Lista Roja IUCN, especie de menor preocupación (Least Concern); NOM-059, aunque menciona algunas subespecies no incluye la presente en Guanajuato. 
5. Lepus callotis Wagler, 1830. Subespecie en Guanajuato: Lepus callotis callotis Wagler, 1830. Existen registros de esta especie para el municipio de Silao (MADUGMA 281 y 288), para Celaya (USNM 78467) y otro para Irapuato (Lozoya Gloria y Uriarte Garzón 2012). Estado de conservación: Lista Roja IUCN, especie casi amenazada (Near Threatened); SEMARNAT-EP-2014, incluida en la lista, lo que ofrece una ventana de oportunidad para promover la restauración ecológica en Guanajuato, sobre todo en áreas extensas dedicadas a la agricultura tecnificada y en la periferia de áreas pobladas e industriales.

6. Sylvilagus audubonii (Baird, 1858). Subespecie en Guanajuato: Sylvilagus audubonii parvulus (J. A. Allen, 1904). Nelson (1909) refiere ejemplares del municipio de Silao (USNM 78982). También se conocen registros para el municipio de San Luis de la Paz (ENCB-IPN) e Irapuato (Lozoya Gloria y Uriarte Garzón, 2012). Estado de conservación: Lista Roja IUCN, especie de menor preocupación (Least Concern).

7. Sylvilagus floridanus (J. A. Allen, 1890). Subespecies en Guanajuato: Sylvilagus floridanus orizabae (Merriam, 1893). Se ha registrado para los municipios de Acámbaro (USNM 34880), Guanajuato (MADUG-MA 268 y 507, y USNM 81711-81715), Santa Catarina (CNMA 21768) y Tierra blanca (CNMA 21869), Victoria (Charre -Medellín et al. 2012) y Xichú (Iglesias et al. 2012). Sylvilagus floridanus subcinctus (Miller, 1899). Existen registros del municipio de Acámbaro (Hall 1981, Apátiga et al. 2008) e Irapuato (LACM 9869). Un ejemplar de Cortázar (CNMA 23019) parece pertenecer a esta subespecie. Estado de conservación: Lista Roja IUCN, especie de menor preocupación (Least Concern).

\section{ORDEN RODENTIA \\ Familia Sciuridae \\ Subfamilia Sciurinae}

8. Glaucomys volans (Linnaeus, 1758). Subespecie en Guanajuato: Glaucomys volans goldmani (Nelson, 1904). Jackson (2012:188) la registró para Guanajuato, aunque no mencionó la localidad específica. Varios registros de Pinal de Amoles, Querétaro (Ceballos et al. 2010), área adyacente al municipio de Atarjea en Guanajuato y con la cual conserva continuidad de hábitat, avalarían el registro de Jackson, al menos para el extremo oriental del estado. Estado de conservación: Lista Roja IUCN, especie de menor preocupación (Least Concern); NOM-059, especie amenazada (A).

9. Ictidomys mexicanus (Erxleben, 1777). Subespecie en Guanajuato: Ictidomys mexicanus mexicanus (Erxleben, 1777). Howell (1938) la citó para el municipio de Silao (USNM 79018-79020). También se conocen ejemplares de los municipios de Acámbaro (KU 63132; MCZ 48573), Celaya (USNM 78455), Guanajuato (MADUG-MA 33, 35 y 154) y Salamanca (CNMA 21068). Lozoya Gloria y Uriarte Garzón (2012) la citan para Irapuato. Elizalde-Arellano et al. (2010) la reportaron de San Luis de la Paz e indicaron que el registro de Salamanca rumbo a Irapuato (CNMA 21068), estaba 
antes asignado a la subespecie Spermophilus m. parvidens; actualmente, en la ficha de catálogo en línea de esa colección el ejemplar aparece como S. m. mexicanus. Estado de conservación: Lista Roja IUCN, especie de menor preocupación (Least Concern) citada como Spermophilus mexicanus.

10. Otospermophilus variegatus (Erxleben, 1777). Subespecie en Guanajuato: Otospermophilus variegatus variegatus (Erxleben, 1777). Howell (1938) la mencionó para el municipio de Silao (USNM 79014). Existen registros de los municipios de Acámbaro (USNM 34924), Guanajuato (USNM 81718 y 81719), Irapuato (Lozoya Gloria y Uriarte Garzón 2012), además de Tierra Blanca (CNMA 21766, 21867 y 21868). También se ha registrado de San Luis de la Paz, cerca de Xichú (ENCB-IPN, Elizalde-Arellano et al. 2010) y de Victoria (Charre-Medellín et al. 2012b). Estado de conservación: Lista Roja IUCN, especie de menor preocupación (Least Concern) citada como Spermophilus variegatus.

11. Sciurus aureogaster F. Cuvier, 1829. Subespecie en Guanajuato: Sciurus aureogaster nigrescens Bennett, 1833. Thorington y Hoffmann (2005) la mencionaron para Guanajuato sin referir localidades particulares. Magaña-Cota et al. (2012) e Iglesias et al. (2012) la mencionan para el municipio de Xichú. Estado de conservación: Lista Roja IUCN, especie de menor preocupación (Least Concern).

12. Sciurus oculatus Peters, 1863. Subespecie en Guanajuato: Sciurus oculatus tolucae Nelson, 1898. Dalquest (1950) la registró para el municipio de Guanajuato. Existen registros de Ocampo y de Guanajuato (CNMA 21069 y 26182, respectivamente). Al parecer existen ejemplares de los municipios de Dolores Hidalgo y de Xichú (en MLZOC, pero la determinación requiere verificarse). Estado de conservación: Lista Roja IUCN, especie de menor preocupación (Least Concern); NOM-059, especie sujeta a protección especial (Pr).

13. Xerospermophilus spilosoma (Bennett, 1833). Subespecie en Guanajuato: Xerospermophilus spilosoma spilosoma (Bennett, 1833). Este taxón está representado por un ejemplar del municipio de Ocampo (CNMA 21805; Magaña-Cota et al. 2012, Sánchez et al. 2014). Estado de conservación: Lista Roja IUCN, especie de menor preocupación (Least Concern) citada como Spermophilus spilosoma.

\section{Familia Heteromyidae Subfamilia Dipodomyinae}

14. Dipodomys merriami Mearns, 1890. Subespecie en Guanajuato: Dipodomys merriami atronasus Merriam, 1894. Se conocen ejemplares del municipio de San Luis de la Paz (ENCB-IPN; Elizalde-Arellano et al. 2010). Estado de conservación: Lista Roja IUCN, especie de menor preocupación (Least Concern); NOM-059, incluye algunas subespecies de este taxón, pero no la que existe en Guanajuato. 
15. Dipodomys ordii Woodhouse, 1853. Subespecie en Guanajuato: Dipodomys ordii palmeri (J. A. Allen, 1891). Se registró previamente del centro-sur del estado (municipio de Celaya; Hall 1981; USNM 78441-78453). Magaña-Cota et al. (2012) la mencionan para San Luis de la Paz. Estado de conservación: Lista Roja IUCN, especie de menor preocupación (Least Concern).

16. Dipodomys ornatus Merriam, 1894. Subespecie en Guanajuato: La especie es monotípica. Para la nomenclatura se sigue a Fernández et al. (2012), quienes recientemente la separaron de $D$. phillipsii dentro de la cual por mucho tiempo se le consideró subespecie (D. p. ornatus Merriam, 1894). Dugès (1908) la registró del municipio de San Diego de la Unión; posiblemente con base en el ejemplar USNM A49406 de la localidad "Quemado", colectado por A. Dugès). También se le ha considerado presente en el centro de Guanajuato (Hall 1981). Existen ejemplares de museo de los municipios de Ocampo (CNMA 21064 y 21383; FMNH 141797 y 141798), León (KU 48979-48986) y San Felipe (MADUG-MA 133 y 158), y también de San Luis de la Paz (ENCB-IPN; Elizalde Arellano et al. 2010). Magaña-Cota et al. (2012) también la mencionan para Ocampo. Estado de conservación: Lista Roja IUCN, fue evaluada todavía como parte de $D$. phillipsii y considerada como especie de menor preocupación (Least Concern), pero necesita evaluarse nuevamente como especie diferente; NOM059, incluye a D. phillipsii como especie sujeta a protección especial ( $\operatorname{Pr}$ ), en función de que considera amenazadas algunas de sus subespecies (no la de Guanajuato, hoy especie diferente $D$. ornatus).

\section{Subfamilia Heteromyinae}

17. Heteromys irroratus Gray, 1868. Subespecie en Guanajuato: Heteromys irroratus alleni Coues, 1881. Homan y Genoways (1978) mencionaron este taxón del municipio de Silao (USNM 78943-78950). En general se le ha considerado presente en todo el estado (Hall 1981). Se conocen ejemplares de otros municipios: Acámbaro (USNM 50324), Moroleón (USNM 15529), Irapuato (Lozoya Gloria y Uriarte Garzón 2012), Guanajuato (CNMA 26573), Santa Catarina (CNMA 21769-21773), Cortázar (CNMA 22627-22632), San Miguel de Allende (CNMA 30828; KU 143798), Salvatierra (KU 66577), San Luis de la Paz(CNMA 21381 y 21382; ENCB-IPN). Magaña-Cota et al. (2012) agregaron Xichú. Estado de conservación: Lista Roja IUCN, como Liomys irroratus, especie de menor preocupación (Least Concern).

\section{Subfamilia Perognathinae}

18. Chaetodipus eremicus (Mearns, 1898). Subespecie en Guanajuato: La especie es monotípica. Los ejemplares disponibles corresponden al municipio de San Luis de la Paz (ENCB-IPN; Elizalde-Arellano et al. 2010). Estado de conservación: Lista Roja IUCN, especie de menor preocupación (Least Concern).

19. Chaetodipus hispidus (Baird, 1858). Subespecie en Guanajuato: Chaetodipus hispidus zacatecae (Osgood, 1900). Andersen y Light (2012) revisaron la filogeografía 
de las poblaciones de esta especie con base en datos mitocondriales, pero la revisión formal de subespecies aún tendría que esperar evidencia más contundente, por ejemplo de marcadores nucleares como microsatélites (Andersen et al. 2012); por ello, aquí se sigue considerando para Guanajuato C. h. zacatecae. Existen ejemplares obtenidos en los municipios de León (KU 48669), Celaya (KU 48670-48675; USNM 78423) y Silao (MADUG-MA 262 y 263). Estado de conservación: Lista Roja IUCN, especie de menor preocupación (Least Concern).

20. Chaetodipus nelsoni (Merriam, 1894). Subespecie en Guanajuato: Chaetodipus nelsoni nelsoni (Merriam, 1894). Los ejemplares conocidos provienen del municipio de San Luis de la Paz (ENCB-IPN; Elizalde-Arellano et al. 2010). Estado de conservación: Lista Roja IUCN, especie de menor preocupación (Least Concern).

21. Perognathus flavus Baird, 1855. Subespecie en Guanajuato: Perognathus flavus medius Baker, 1954. Existen registros de los municipios de Celaya (USNM 78425 y 78426 ; KU 48596-48603) y León (KU 48591-48595); ambos municipios fueron mencionados por Hall (1981). Además se conocen ejemplares del municipio de Guanajuato (USNM 62024, 60071-60073; al parecer también de éste, el ejemplar AMNH MS-989) y de Silao (MADUG-MA 180). Elizalde-Arellano et al. (2010) la citaron para San Luis de la Paz (ENCB-IPN 43374). Magaña-Cota et al. (2012) refieren para el estado la subespecie P. flavus hopiensis, sin embargo ésta sólo se conoce de la confluencia de los estados de Arizona, Nuevo México, Colorado y Utah en los Estados Unidos de Norteamérica (Best y Skupski 1994), por lo que aquí no se considera parte de la mastofauna de Guanajuato. Estado de conservación: Lista Roja IUCN, especie de menor preocupación (Least Concern).

\section{Familia Geomyidae}

22. Cratogeomys fumosus (Merriam, 1892). Subespecies en Guanajuato: C. fumosus angustirostris (Merriam, 1903). Se ha registrado del municipio de Celaya (2 mi E Celaya, 5800 ft, Guanajuato; Hafner et al. 2004) y existen ejemplares de San Diego de la Unión (MADUG-MA 155 y 356, USNM 13301). Otros más también son de Celaya (KU 48537 y 48538, 66148-66153; LSUMZ 36092). C. fumosus tylorhinus (Merriam, 1903). Apátiga et al. (2008) la reportaron para Acámbaro. Se ha registrado de un área de Querétaro inmediatamente contigua al municipio guanajuatense de Atarjea (Cerro de la Calentura, about 8 miles NW de Pinal de Amoles, Querétaro, México; Hafner et al. 2004), por lo que podría hallarse también en el extremo oriental de Guanajuato. Estado de conservación: Lista Roja IUCN, especie de menor preocupación (Least Concern); NOM-059, Amenazada (A), pero necesitará reevaluarse en la Norma, pues antes C. fumosus era considerada una especie distinta de C. tylorhinus; hoy C. fumosus incluye a C. tylorhinus sólo como una subespecie.

23. Thomomys umbrinus (Richardson, 1829). Subespecie en Guanajuato: Thomomys umbrinus supernus Nelson y Goldman, 1934. Se considera endémica de la Sierra de Santa Rosa (Hall 1981; USNM 81680-81688), la cual comprende buena parte del norte 
del municipio de Guanajuato y una porción del extremo sur del de San Felipe. MagañaCota et al. (2012) refieren la presencia de la especie T. umbrinus en localidades del oeste del estado (8.04 km SO; 26 km SW y $12.87 \mathrm{~km}$ SW Ibarra) pero no mencionan la fuente de esas localidades; una vez conocida la ubicación de los ejemplares en que se basan esos registros, será de interés verificar su identidad. Por otra parte, evidencia molecular estudiada por Álvarez-Castañeda (2010) indica que el complejo Thomomys bottaeumbrinus en realidad podría incluir más de dos especies, por lo que las poblaciones de Guanajuato necesitan ser reevaluadas bajo esa perspectiva. Estado de conservación: Lista Roja IUCN, como T. umbrinus, especie de menor preocupación (Least Concern).

\section{Familia Cricetidae Subfamilia Neotominae}

24. Baiomys taylori (Thomas, 1887). Subespecie en Guanajuato: Baiomys taylori analogus (Osgood, 1909). Se ha registrado del municipio de León (Hall, 1981).También existen ejemplares de Acámbaro (KU 62971-62980; USNM 50673-50675; ENCB-IPN), Celaya (KU 49514-49519; ENCB-IPN), Cortázar (CNMA 22633-22635), y Guanajuato (CNMA 27940), León (KU 49484-49513), Salamanca (UMMZ 95707 y 95708), Salvatierra (KU 66950-66953, ENCB-IPN), Yuriria (KU 66954-66960; CAS 12438-12442, originalmente determinados como B. taylori allex), Dolores Hidalgo y San Luis de la Paz (ENCB-IPN; Elizalde-Arellano et al. 2010) e Irapuato (Lozoya Gloria y Uriarte Garzón 2012). Estado de conservación: Lista Roja IUCN, especie de menor preocupación (Least Concern).

25. Neotoma leucodon Merriam, 1894. Subespecie en Guanajuato: Neotoma leucodon leucodon Merriam, 1894. Se le registró en el municipio de San Felipe (Hall 1981; USNM 56456-56458, colectados por A. Dugès) y más recientemente del municipio de San Luis de la Paz (ENCB-IPN, Elizalde-Arellano et al. 2010). Otros ejemplares de museo confirman su presencia en los municipios de: Guanajuato (MADUG-MA 508), Ocampo (CNMA 21384), Santa Catarina (CNMA 21774) y Tierra Blanca (CNMA 21775). Magaña-Cota et al. (2012) refieren la presencia de N. leucodon de Jaral del Progreso. NOTA: Además de $N$. leucodon estos últimos autores también mencionan un registro de Acámbaro como N. albigula pero esta especie, como se le entiende actualmente, sólo existe del norte de Sinaloa y Sur de Chihuahua y de allí al norte hacia territorio norteamericano (Edwards et al. 2001); por lo anterior N. albigula no se considera parte de la fauna de Guanajuato. Estado de conservación: Lista Roja IUCN, especie de menor preocupación (Least Concern).

26. Neotoma mexicana Baird, 1855. Subespecies en Guanajuato: Neotoma mexicana tenuicauda Merriam, 1892. Varios ejemplares del municipio de Irapuato (MLZ-OC) al parecer podrían corresponder a esta subespecie, pero esto requiere confirmarse mediante registros adicionales. Neotoma mexicana torquata Ward, 1891. Existen ejemplares del municipio de San Luis de la Paz (ENCB-IPN; Elizalde-Arellano et al. 2010) y registros para Ocampo (CNMA 21070), Victoria y Xichú en Magaña-Cota et al. (2012) que pueden asignarse geográficamente a esta subespecie. Estado de conservación: Lista Roja IUCN, especie de menor preocupación (Least Concern). 
27. Oryzomys albiventer Merriam, 1901. Subespecie en Guanajuato: La especie es monotípica. Existe un registro del municipio de Salvatierra (Carleton y Arroyo-Cabrales 2009; KU 66597). Un ejemplar de Yuriria (CAS 12302) puede ser referible a esta especie. Además, un registro arqueológico para el municipio de Abasolo, originalmente referido a Oryzomys fulvescens (Álvarez y Ocaña 1999), también puede pertenecer a O. albiventer. En su revisión de los roedores de Guanajuato Magaña-Cota et al. (2012) mencionan esta especie de Puente de Ixtla, pero esa localidad pertenece al estado de Morelos y no a Guanajuato. Estado de conservación: Lista Roja IUCN, esta especie no ha sido evaluada como tal; NOM-059, no incluye albiventer ni como subespecie de Oryzomys couesi, especie de la cual antes fue considerada parte.

28. Peromyscus difficilis (J. A. Allen, 1891). Subespecie en Guanajuato: Peromyscus difficilis difficilis (J. A. Allen, 1891). Se ha registrado de los municipios de Guanajuato (Hall 1981, USNM 81689-81701 y 81703-81709; TCWC 40473 y 40474; CAS 1232412326, 12385-12388 y 12422) y de Ocampo (Baker 1969; CNMA 21081-21102, 21392-21404, 21406-21412, 30825). También existen ejemplares de San Luis de la Paz (CNMA 21405), Dolores Hidalgo (CNMA 23858) y San Miguel de Allende (CNMA 23834-23848, 25994 y 31961), de San Luis de la Paz (IPN-ENCB; Elizalde-Arellano et al. 2010), de San Felipe (KU 143793) y San José Iturbide (TTU 12566). Apátiga et al. (2008) la reportaron para Acámbaro. Magaña-Cota et al. (2012) la refieren de los municipios de San José [Iturbide], León y Xichú. Estado de conservación: Lista Roja IUCN, especie de menor preocupación (Least Concern).

29. Peromyscus eremicus (Baird, 1858). Subespecie en Guanajuato: Peromyscus eremicus phaeurus Osgood, 1904. Se conoce solamente del municipio de San Luis de la Paz (ENCB-IPN; Elizalde-Arellano et al. 2010). Estado de conservación: Lista Roja IUCN, especie de menor preocupación (Least Concern); NOM-059, no incluye la subespecie presente en Guanajuato.

30. Peromyscus gratus Merriam, 1898. Subespecies en Guanajuato: Peromyscus gratus gentilis Osgood, 1904. Se ha registrado principalmente de la mitad oeste del estado (municipio de Silao, Hall 1981; USNM 78915-78917). Baker (1969) lo reportó de Ocampo. Otros ejemplares asignables geográficamente a esta subespecie son de los municipios de Guanajuato (CNMA 13762) y Ocampo (CNMA 21417-21421), Manuel Doblado (CNMA 23859-23870, 23875-23878), de Pénjamo (CNMA 23872-23874), de León (KU 49235-49241; MADUG-MA 259) y algunos ejemplares de Dolores Hidalgo (CNMA 23871, 23891-23893) podrían ser limítrofes con otra subespecie, comentada a continuación. Peromyscus gratus gratus Merriam, 1898. Geográficamente pueden asignarse a esta subespecie ejemplares de los municipios de Cortázar (CNMA 22616, 22637-22642 y 22739-22749), San Miguel de Allende (CNMA 23879-23889), Tierra Blanca (CNMA 21783- 21801), Guanajuato (CNMA 33592) y de Acámbaro (KU 6284862850; y ejemplares de ENCB-IPN). Se ha registrado también de San Diego de La Unión y San Luis de la Paz (CNMA 21416; Elizalde-Arellano et al. 2010), y de Xichú (ENCBIPN; Elizalde-Arellano et al. 2010). Estado de conservación: Lista Roja IUCN, especie de menor preocupación (Least Concern). 
31. Peromyscus hylocetes Merriam, 1898. Subespecies en Guanajuato: Esta especie es monotípica. Existen ejemplares de los municipios de Pénjamo (CNMA 23832) y Cortázar (CNMA 23833). Apátiga et al. (2008) la reportaron de Acámbaro. Estado de conservación: Lista Roja IUCN, especie de menor preocupación (Least Concern).

32. Peromyscus levipes Merriam, 1898. Subespecie en Guanajuato: Peromyscus levipes levipes Merriam, 1898. Hall (1981) lo citó del municipio de Ocampo, con base en un registro de Brown y Welser (1968). Existen ejemplares provenientes de los municipios de Acámbaro (KU 99002), Coroneo (CNMA 39324-39327), Cortázar (22598-22615, 22617-22623, 23018 y 25991), San Miguel de Allende (CNMA 31962 y 31963), Tierra Blanca (CNMA 21806-21819, 21861, 21864-21865), Santa Catarina (CNMA 21863) y Victoria (CNMA 21072-21073, 21075, 21079 y 21080, 21385-21391, y 21422), de Guanajuato (ENCB-IPN, Elizalde-Arellano et al. 2010; CNMA 33240), San Luis de la Paz (ENCB-IPN, Elizalde-Arellano et al. 2010; CNMA 21071, 21076-21078 y 39323) y Pénjamo (CNMA 39328 y 39329). Magaña-Cota et al. (2012) agregan Yuriria. Estado de conservación: Lista Roja IUCN, especie de menor preocupación (Least Concern).

33. Peromyscus maniculatus (Wagner, 1845). Subespecie en Guanajuato: Peromyscus maniculatus labecula Elliot, 1903. Osgood (1909) lo registró para los municipios de Guanajuato (existen ejemplares en USNM: 13127, 60384 y 81702), Irapuato (USNM 78919-78924, 80351 y 81678) y Silao (USNM 78918). Baker (1969) lo reportó para el municipio de Ocampo, y Genoways y Jones (1971) lo registraron para León. Un mapa en Hall (1981) lo supone presente en casi todo el estado; hasta la fecha existen otros registros asignables a $P$. m. labecula de los municipios de Celaya (KU 49316-49327 y 66765-66768), de Guanajuato (CAS 12338), Irapuato (KU 38534-38567y Lozoya Gloria y Uriarte Garzón 2012); de León (KU 49313-49315), Salvatierra (ENCB-IPN, ElizaldeArellano et al. 2010 y KU 66769 y 66775-66781), de San Diego de la Unión (MADUGMA 257), Ocampo (CNMA 21413) y Pénjamo (CNMA 23849 y 23850), de San Luis de la Paz (ENCB-IPN, Elizalde-Arellano et al. 2010) y de Yuriria (CNMA 27077 y 27078; KU 66782 y 66783; CAS 12333 y 12334, 12341, 12353, 12412, 12416, 12419, 12423 y 12424). Apátiga et al. (2008) la registraron para Acámbaro. El mapa en Hall (1981) entreabre la posibilidad de que en el extremo norte del estado pueda existir la subespecie P. m. blandus, pero no menciona localidades. Dos ejemplares de León en KU (49459 y 49632) originalmente fueron determinados como $P$. m. blandus pero, dado que son de la misma localidad y fecha que los arriba citados, puede tratarse de un error. Existen otros ejemplares de Guanajuato, de los que no se consigna una localidad específica (TCWC 40434-40438); fueron colectados por J.W. Bickham, quien trabajó en el centro del estado en 1977 y 1978. Estado de conservación: Lista Roja IUCN, especie de menor preocupación (Least Concern); la NOM-059, no incluye a las subespecies presentes en Guanajuato.

34. Peromyscus melanophrys (Coues, 1874). Subespecies en Guanajuato: Peromyscus melanophrys consobrinus Osgood, 1904. Se ha registrado de Silao (Hall, 1981; USNM 
78966-78968). Ejemplares colectados en los municipios de Guanajuato (MADUG-MA 509, USNM 18412-18414), de León (KU 49390 y 49391), de Dolores Hidalgo (CNMA 23853-23857) y Guanajuato (CNMA 33996) pueden asignarse a esta subespecie. Peromyscus melanophrys zamorae Osgood, 1904. El mapa de Hall (1981) lo supone presente en el centro-sur de Guanajuato, pero no menciona registros. Existen ejemplares que pueden considerarse asignables a esta subespecie, de los municipios de Acámbaro (KU 112360; MCZ 48576) y Celaya (KU 66804), Cortázar (CNMA 22643-22647) y San José Iturbide (TTU 9864). Ciertos ejemplares de Manuel Doblado (CNMA 23851 y 23852) pueden pertenecer a zamorae aunque podrían resultar intermedios con P. m. consobrinus. Magaña-Cota et al. (2012) agregan registros de $P$. m. zamorae paraYuriria y Xichú. Varios ejemplares del noreste del estado (San Luis de la Paz, ENCB-IPN, Elizalde-Arellano et al. 2010) se asignaron a esta subespecie. Estado de conservación: Lista Roja IUCN, especie de menor preocupación (Least Concern).

35. Peromyscus melanotis J. A. Allen y Chapman, 1897. Subespecies en Guanajuato: La especie es monotípica. Existen ejemplares de los municipios de Cortázar (CNMA 2262422626), Tierra Blanca (CNMA 21779) y León (MADUG-MA 302). Apátiga et al. (2008) informaron de su presencia en Acámbaro. Magaña-Cota et al. (2012) adicionaron Yuriria. Estado de conservación: Lista Roja IUCN, especie de menor preocupación (Least Concern).

36. Peromyscus pectoralis Osgood, 1904. Subespecies en Guanajuato: Peromyscus pectoralis collinus Hooper, 1952. Se conoce solamente del municipio de Ocampo (Hall 1981). Peromyscus pectoralis pectoralis Osgood, 1904. Hall (1981) la supone presente en el centro del estado. Existen ejemplares de los municipios de Dolores Hidalgo (CNMA 23894 y 23895, 39334-39337), Manuel Doblado (CNMA 39338), Santa Catarina (CNMA 21820-21842, 21860, 22347 y 22348), Tierra Blanca (CNMA 21780-21782) y Xichú (CNMA 21414-21415), de Guanajuato y San Luis de la Paz (ENCB-IPN, Elizalde-Arellano et al. 2010; TTU 36204); otros son de Irapuato (MLZ-OC) y también podrían corresponder a esta subespecie, pero necesitan revisión. Estado de conservación: Lista Roja IUCN, especie de menor preocupación (Least Concern).

37. Reithrodontomys fulvescens J. A. Allen, 1894. Subespecies en Guanajuato: Reithrodontomys fulvescens griseoflavus Merriam, 1901. Se le ha considerado presente en el centro-norte del estado (Hall 1981). Existen ejemplares referibles a esta subespecie de los municipios de Dolores Hidalgo (CNMA 23896), León (KU 49039-49044), Celaya (KU 66654; ENCB-IPN), Salvatierra, Guanajuato, y de San Luis de la Paz (ENCB-IPN; Elizalde-Arellano et al. 2010). Algunos ejemplares del municipio de Guanajuato se han determinado como R. f. griseoflavus (ENCB-IPN; Elizalde-Arellano et al. 2010) y otros como R.f. toltecus (CNMA, abajo), por lo que se requiere revisar más material de esa área para clarificar su identidad y revisar los límites geográficos de las subespecies. MagañaCota et al. (2012) citan Salvatierra y Xichú como parte de la distribución conocida de R. f. griseoflavus. También hay materiales de Silao (MADUG-MA 264 y 265; USNM 78940 y 80352). Reithrodontomys fulvescens toltecus Merriam, 1901. Esta subespecie se conoce del sur del estado, de los municipios de Acámbaro (Hall 1981; KU 62650; USNM 50719 y 50720), de Cortázar (CNMA 23014-23017), Guanajuato (CNMA 31169) 
y Yuriria (CAS 12313 y 12314). Estado de conservación: Lista Roja IUCN, especie de menor preocupación (Least Concern).

38. Reithrodontomys megalotis (Baird, 1858). Subespecies en Guanajuato:

Reithrodontomys megalotis megalotis (Baird, 1858). Se le ha supuesto presente en una amplia región del centro del estado, aunque sólo con base en un registro del municipio de Guanajuato (Hall 1981) que aparentemente se refiere a un solo ejemplar de museo (USNM 81710). Reithrodontomys megalotis saturatus J. A. Allen y Chapman, 1897. De acuerdo con el mapa de Hall (1981) esta subespecie se relacionaría con en el sur y el este del estado; esto parece confirmarse con la presencia de ejemplares de los municipios de San Luis de la Paz (ENCB-IPN; Elizalde-Arellano et al. 2010) y de Yuriria (KU 66656 y 66657). Estado de conservación: Lista Roja IUCN, especie de menor preocupación (Least Concern).

\section{Subfamilia Sigmodontinae}

39. Sigmodon fulviventer J. A. Allen, 1889. Subespecie en Guanajuato: La especie se considera monotípica. Se le supone presente en la mitad occidental del estado (Hall 1981). Baker (1969) la citó para el municipio de Ocampo y Magaña-Cota et al. (2012) para Yuriria. Estado de conservación: Lista Roja IUCN especie de menor preocupación (Least Concern).

40. Sigmodon (complejo S. hispidus). Situación en Guanajuato: Henson y Bradley (2009) resumen la evidencia molecular y morfológica reciente sobre Sigmodon, la cual reconoce que existe un grupo complejo de especies cercanas a S. hispidus (Clado I de esos autores). Conforme a los resultados de Peppers y Bradley (2000), Peppers et al. (2002), Carroll y Bradley (2005) y Carroll et al. (2005), la presencia de S. hispidus (sensu stricto) quedaría descartada en la Altiplanicie Mexicana; otras especies afines conocidas de regiones cercanas al Bajío y al norte de Michoacán (S. alleni y S. mascotensis) pueden hallarse en Guanajuato y quizá pudieron haber sido registradas como S. hispidus en el pasado. Baker (1969) mencionó S. hispidus de Ibarra, municipio de Ocampo y Zimmermann (1970) la refirió de Celaya (KU 66984 y 66985). Hall (1981) citó a S. $h$. (berlandieri) también de Celaya. En general existe considerable incertidumbre acerca de la identidad taxonómica y distribución de varias especies y poblaciones de Sigmodon en México (Ramírez-Pulido et al. 2005, Henson y Bradley 2009). Elizalde et al. (2010) también encontraron problemática la identidad de ejemplares de Sigmodon que estudiaron de los municipios de Guanajuato, San Diego de la Unión y Celaya, los cuales terminaron por reportar provisionalmente como S. hispidus berlandieri. Magaña-Cota et al. (2012) mencionaron ejemplares de Acámbaro, León y Xichú como S. hispidus. La confusión persiste y será necesario revisar críticamente materiales de Guanajuato anteriormente determinados como S. hispidus, por ejemplo de Celaya (ENCB-IPN, KU, arriba mencionados), Guanajuato (ENCB-IPN), San Diego de la Unión (ENCB-IPN) y de Yuriria (CAS 12447). Por otra parte, Magaña-Cota et al. (2012) incluyeron para el estado un registro de Sigmodon ochrognathus, pero esta última especie, del Clado I de Henson y Bradley (2009), sólo se conoce de la Sierra Madre Occidental, entre Arizona 
y el extremo noroeste de Zacatecas (Linzey et al. 2008). Aunque efectivamente existe en un ejemplar de Sigmodon obtenido en El Capulín, municipio de Guanajuato (TCWC 40486, rotulado originalmente como $S$. ochrognathus) una vez revisado resultó referible a lo que antes se conoció en sentido amplio como S. hispidus (Jessica Light y Fred Stangl, com. pers. 2013). Existe un ejemplar más del municipio de Guanajuato (USNM 13121, colectado por A. Dugès y determinado como S. hispidus). Todo el material de Sigmodon cf. hispidus de Guanajuato continúa en gran necesidad de estudio crítico. Estado de conservación: La evaluación efectiva de Sigmodon (complejo S. hispidus) requiere esperar la clarificación general de la sistemática del grupo.

41. Sigmodon leucotis Bailey, 1902. Subespecies en Guanajuato: La especie se considera monotípica. Con base en registros de la periferia del estado de Guanajuato, se le ha considerado presente en la mayor parte del estado, con la posible excepción del extremo suroeste (Hall 1981), aunque no se han consignado localidades específicas. Estado de conservación: Lista Roja IUCN, especie de menor preocupación (Least Concern).

\section{ORDEN SORICOMORPHA \\ Familia Soricidae \\ Subfamilia Soricinae}

42. Cryptotis parva (Say, 1823). Subespecie en Guanajuato: Cryptotis parva berlandieri (Baird, 1858). Este taxón era conocido sólo del centro del estado (Hall 1981) con base en un registro del municipio de Guanajuato (USNM 15565). Apátiga et al. (2008) la mencionaron para Acámbaro. Estado de conservación: Lista Roja IUCN, especie de menor preocupación (Least Concern); NOM-059, no incluye a la subespecie presente en Guanajuato.

43. Sorex saussurei Merriam, 1892. Subespecie en Guanajuato: Sorex saussurei saussurei Merriam, 1892. Se le ha considerado presente virtualmente en todo el estado (Hall, 1981), aunque los ejemplares conocidos provienen solamente de dos municipios, Guanajuato (USNM 81616) y San Luis de la Paz (ENCB-IPN). Estado de conservación: Lista Roja IUCN, especie de menor preocupación (Least Concern).

\section{ORDEN CARNIVORA \\ Familia Felidae \\ Subfamilia Felinae}

44. Herpailurus yagouaroundi (Lacépède, 1809). Varios autores asignan esta especie al género Puma (Wilson y Reeder, 2005). Subespecie en Guanajuato: Herpailurus yagouaroundi cacomitli (Berlandier, 1859). Esta subespecie se ha registrado fotográficamente del área de la Sierra Gorda en el municipio de Victoria (IBUNAM: CFBFB 3950; Charre-Medellín et al. 2012a). NOTA: es probable que en el oeste del Bajío guanajuatense exista otra subespecie: $H$. yagouaroundi tolteca (Thomas, 1898), la cual se distribuye en la vertiente del Pacífico y corresponde a registros de varias regiones de Jalisco, incluyendo el oriente de esa entidad adyacente al suroeste de Guanajuato 
(Íñiguez-Dávalos y Santana-Castellón 2005); no obstante, será necesario documentar si está presente en Guanajuato. Estado de conservación: Lista Roja IUCN, especie de menor preocupación (Least Concern); NOM-059, amenazada (A); CITES, Apéndice I como miembro de las poblaciones de América Central y América del Norte (las demás poblaciones están incluidas en el Apéndice II).

45. Leopardus pardalis (Linnaeus, 1758). Subespecies en Guanajuato: Leopardus pardalis pardalis (Linnaeus, 1758). Se conoce del este del estado, de la Sierra Gorda en su vertiente hacia el Golfo de México, mediante registro fotográfico del municipio de Xichú (IBUNAM: CFBFB1077 e IBUNAM: CFBFB1185; Iglesias et al. 2008, Iglesias et al. 2012). Leopardus pardalis nelsoni (Goldman, 1925). Esta subespecie se distribuye en el oeste de México. El registro de la especie por A. Dugès (1890) para el sur de Guanajuato (presumiblemente el ejemplar MADUG-MA 101; Tupátaro, Municipio de Cuerámaro, con base en los cuadernos de notas de este autor) correspondería a esta subespecie. Estado de conservación: Lista Roja IUCN, especie de menor preocupación (Least Concern); NOM-059, en peligro (P); CITES: Apéndice I.

46. Leopardus wiedii (Schinz, 1821). Subespecie en Guanajuato: Leopardus wiedii oaxacensis (Nelson y Goldman, 1931). El único registro actual de la especie en el estado es fotográfico, obtenido de la Sierra Gorda dentro del Municipio de Xichú (IBUNAM: CFBFB1068 e IBUNAM: CFB FB1301; Iglesias et al. 2008, Iglesias et al. 2012) y correspondería a esta subespecie. Estado de conservación: Lista Roja IUCN, especie casi amenazada (Near Threatened); NOM-059, en peligro (P); CITES, Apéndice I.

47. Lynx rufus (Schreber, 1777). Subespecie en Guanajuato: Lynx rufus escuinapae J. A. Allen, 1903. Se han registrado ejemplares en los municipios de Guanajuato (MADUGMA 111) y San Luis de la Paz (ENCB-IPN); también de la Sierra Gorda al oriente del estado (IBUNAM: CFB:FB1883 e IBUNAM: CFB:FB2030, municipio de Victoria; CharreMedellín et al.2012b). Apátiga et al. (2008) la registraron para Acámbaro, Lozoya Gloria y Uriarte Garzón (2012) para Irapuato, y Cecaira-Ricoy et al. (2012) para Xichú. Estado de conservación: Lista Roja IUCN, especie de menor preocupación (Least Concern); CITES: Apéndice II, como miembro de la familia Felidae.

48. Puma concolor (Linnaeus, 1771). Subespecie en Guanajuato: Puma concolor aztecus (Merriam, 1901). Se conoce de los municipios de Acámbaro (Apátiga et al. 2008), de Guanajuato (MADUG-MA 534), Victoria (IBUNAM: CFBFB2082); CharreMedellín et al.2012) y Xichú (IBUNAM: CFBFB1256 e IBUNAM: CFB FB1305; Iglesias et al. 2012). Estado de conservación: Lista Roja IUCN, especie de menor preocupación (Least Concern); CITES: Apéndice II, como miembro de la familia Felidae.

\section{Familia Canidae}

49. Canis latrans Say, 1823. Subespecies en Guanajuato: Canis latrans cagottis (Hamilton-Smith, 1839). De acuerdo con el mapa de Hall (1981) podría hallarse en la mitad este del estado. Un ejemplar del municipio de Guanajuato (MADUG-MA 2) puede asignarse geográficamente a esta subespecie, así como los reportes de Charre- 
Medellín et al. (2012b) para los municipios de Victoria (IBUNAM: CFB:FB2007) y de Cecaira-Ricoy et al. (2012) para Xichú. Apátiga et al. (2008) también lo citaron para Acámbaro. Canis latrans impavidus J. A. Allen, 1903. El mapa de Hall (1981) supone la presencia de esta subespecie en el occidente del estado. Un registro de Lozoya Gloria y Uriarte Garzón (2012) para Irapuato podría resultar asignable a esta subespecie, pero se requiere examinar ejemplares de esa región. Estado de conservación: Lista Roja IUCN, especie de menor preocupación (Least Concern).

50. *Canis lupus Linnaeus, 1758. Subespecie en Guanajuato: Canis lupus baileyi Nelson y Goldman, 1929. Esta es la subespecie que existió en el estado, de acuerdo con Hall (1981). Sólo se conocen ejemplares del municipio de Cuerámaro (MADUG-MA 4 y 5), obtenidos en el Siglo XIX o al inicio del XX. Estado de conservación: Lista Roja IUCN, especie de menor preocupación (Least Concern); NOM-059, probablemente extinta en el medio silvestre (E); CITES, la población de México queda comprendida en el texto del Apéndice II; SEMARNAT-EP-2014, enlistada (aunque para Guanajuato sólo tendría sentido mediante restauración previa del hábitat, reconstrucción de la base de presas y un cuidadoso programa de reintroducción, que incluyera consideraciones de seguridad humana y educación para la conservación).

51. Urocyon cinereoargenteus (Schreber, 1775). Subespecie en Guanajuato: Urocyon cinereoargenteus nigrirostris (Lichtenstein, 1850). Esta es la única subespecie que se halla en territorio del estado (Hall1981). Existen ejemplares de los municipios de Guanajuato (MADUG-MA 28, 88, 89, 311 y 523; CNMA 7076) y León (MADUG-MA 223). Apátiga et al. (2008) informaron de su presencia en Acámbaro. Lozoya Gloria y Uriarte Garzón (2012) la citan para Irapuato. Charre-Medellín et al. (2012) para Victoria e Iglesias et al. (2012) para Xichú. Estado de conservación: Lista Roja IUCN, especie de menor preocupación (Least Concern).

\section{Familia Mustelidae Subfamilia Lutrinae}

52. *Lontra longicaudis (Olfers, 1818). Subespecie en Guanajuato: Lontra longicaudis annectens (Major, 1897). Esta es la única subespecie presente en el país y por tanto la que existió al menos en tiempos históricos en el suroeste de Guanajuato, probablemente en el municipio de Pénjamo de acuerdo con un registro de Dugès en el que refiere el Río Lerma (Magaña-Cota, 2008:53). Se le ha considerado extirpada del estado, aunque es posible que aún pueda existir en tramos relativamente conservados de ríos de esa región del estado, como ha ocurrido en otras entidades federativas (Gallo 1997; Sánchez et al. 2007; Monroy-Vilchis y Mundo 2009; Charre-Medellín et al. 2011). Estado de conservación: Lista Roja IUCN, con datos deficientes (Data Deficient); NOM-059, amenazada (A); CITES, Apéndice I; SEMARNAT-EP-2014, incluida en el listado, en caso de que se encontrara alguna población remanente en Guanajuato requeriría un programa emergente de conservación del hábitat y de sus recursos de alimentación, además de asegurar la protección efectiva de la eventual población. 


\section{Subfamilia Mustelinae}

53. Mustela frenata Lichtenstein, 1831. Subespecie en Guanajuato: Mustela frenata frenata Lichtenstein, 1831. Hall (1981) indica que esta subespecie estaría presente en la mayor parte del territorio estatal, excepto donde se encuentre $M$. f. leucoparia. Se conocen ejemplares provenientes de los municipios de Acámbaro (KU 63122-63125) y Guanajuato (MADUG-MA 132). Lozoya Gloria y Uriarte Garzón (2012) citan un registro para Irapuato, que podría ser asignable a esta subespecie. NOTA: Con base en un registro documentado de 4 1/2 mi NE de Comanja de Corona, Jalisco (Genoways y Jones 1973, p. 19) sitio ubicado en el límite con Guanajuato, podría suponerse presente la subespecie Mustela frenata leucoparia (Merriam, 1896) en la región occidental del estado; no obstante, será necesario verificarlo con ejemplares de esa área de Guanajuato. Estado de conservación: Lista Roja IUCN, especie de menor preocupación (Least Concern).

\section{Subfamilia Taxidiinae}

54. Taxidea taxus (Schreber, 1777). Subespecie en Guanajuato: Taxidea taxus berlandieri Baird, 1858. Esta subespecie, de amplia distribución en el país, excepto en el sureste es la que se encuentra en el estado y fue registrada por Dugès (1874) para el municipio de Silao. El único ejemplar de museo de que se tiene noticia (MADUG-MA 60) no refiere la localidad de origen, pero es posible que sea el que estudió Dugès. Estado de conservación: Lista Roja IUCN, especie de menor preocupación (Least Concern); NOM059, amenazada (A).

\section{Familia Mephitidae}

55. Conepatus leuconotus (Lichtenstein, 1832). Subespecie en Guanajuato: Conepatus leuconotus leuconotus (Lichtenstein, 1832). Esta es la única subespecie presente en el país. Se conocen ejemplares del municipio de Guanajuato (MADUG-MA 83, USNM 81721). Apátiga et al. (2008) la reportaron para Acámbaro. Charre-Medellín et al. (2012) para Victoria (IBUNAM: CFB:FB 2115), e Iglesias et al. (2012) para Xichú (IBUNAM: CFB:FB 1081). Estado de conservación: Lista Roja IUCN, especie de menor preocupación (Least Concern).

56. Mephitis macroura Lichtenstein, 1832. Subespecie en Guanajuato: Mephitis macroura macroura Lichtenstein, 1832. Esta subespecie se distribuye ampliamente en el centro de México. Existen ejemplares del municipio de San Miguel de Allende (CNMA 30726 y 32025). Apátiga et al. (2008) la incluyen en su lista para Acámbaro; Lozoya Gloria y Uriarte Garzón (2012) citan Irapuato, Charre-Medellín et al. (2012b) Victoria (IBUNAM: CFB:FB 2064, IBUNAM:CFB:FB 2087 e IBUNAM:CFB:FB 2089), y CecairaRicoy et al. (2012) Xichú. Estado de conservación: Lista Roja IUCN, especie de menor preocupación (Least Concern).

57. Spilogale gracilis Merriam, 1890. Subespecie en Guanajuato: Spilogale gracilis leucoparia Merriam, 1890. La presencia de esta subespecie se ha documentado para 
el municipio de Guanajuato (Hall y Kelson 1959, ejemplares USNM 81716 y 81717 ) y otros (MADUG-MA 212); y también para San Miguel de Allende (CNMA 30727-30729). Apátiga et al. (2008) la registraron para Acámbaro y Cecaira-Ricoy et al. (2012) para Victoria. Estado de conservación: Lista Roja IUCN, especie de menor preocupación (Least Concern).

\section{Familia Procyonidae Subfamilia Procyoninae}

58. Bassariscus astutus (Lichtenstein, 1830). Subespecies en Guanajuato: Bassariscus astutus astutus (Lichtenstein, 1830). Se ha asumido la presencia de esta subespecie en la mitad noreste del estado (Hall 1981). Existen ejemplares del municipio de Tierra Blanca (CNMA 21870-21872). Los registros para Victoria (IBUNAM:CFB:FB 2056, CharreMedellín et al. 2012b) y Xichú (IBUNAM:CFB:FB 1088, Iglesias et al. 2012) pueden asignarse geográficamente a esta subespecie. Bassariscus astutus consitus Nelson y Goldman, 1932. El mapa en Hall (1981) supone presente esta subespecie en la mitad suroeste del estado. Pueden asignarse geográficamente a esta subespecie especímenes obtenidos en los municipios de Guanajuato (MADUG-MA 213) y Manuel Doblado (CNMA 30725 y 31989), así como los registros de Lozoya Gloria y Uriarte Garzón (2012) para Irapuato y de Apátiga et al. (2008) para Acámbaro. Estado de conservación: Lista Roja IUCN, especie de menor preocupación (Least Concern); NOM-059, no incluye a las subespecies presentes en Guanajuato.

59. Nasua narica (Linnaeus, 1766). Subespecie en Guanajuato: Nasua narica molaris Merriam, 1902. Hall (1981) no incluyó Guanajuato en la distribución de esta especie, sin embargo actualmente existen registros de Acámbaro (Apátiga et al. 2008), de Victoria (IBUNAM:CFB:FB 1940, Charre-Medellín et al. 2012b) y de Xichú (IBUNAM:CFB:FB 1250, Iglesias et al. 2012) que corresponderían a esta subespecie. Estado de conservación: Lista Roja IUCN, especie de menor preocupación (Least Concern); NOM-059, no incluye la subespecie presente en Guanajuato; CITES, no incluye las poblaciones de México.

60. Procyon Iotor (Linnaeus, 1758). Subespecie en Guanajuato: Procyon lotor hernandezii Wagler, 1831. Esta subespecie tiene amplia distribución en el centro del país y se le supone presente en todo el territorio estatal (Hall 1981). Existen ejemplares de los municipios de Acámbaro (USNM A47782 y A47783), Guanajuato (MADUG-MA 65, 109 y 123) y San Diego de la Unión (MADUG-MA 24), así como registros de Irapuato (Lozoya Gloria y Uriarte Garzón, 2012), de Victoria (Charre-Medellín et al. 2012b) y de Xichú (Iglesias et al. 2012). Estado de conservación: Lista Roja IUCN, especie de menor preocupación (Least Concern).

\section{ORDEN ARTIODACTYLA \\ Familia Tayassuidae}

61. Pecari tajacu (Linnaeus, 1758). Subespecie en Guanajuato: Pecari tajacu angulatus (Cope, 1889). Hall (1981) asignó a esta subespecie material de aproximadamente 15 millas al S de San Bartolo de Berrio (municipio de San Felipe). También se conocen 
ejemplares de los municipios de Cuerámaro (MADUG-MA 8) y Victoria (ENCB-IPN; Charre-Medellín et al. 2012b). Estado de conservación: Lista Roja IUCN, especie de menor preocupación (Least Concern); CITES, las poblaciones de México quedan explícitamente excluidas de los Apéndices CITES, no así las de otros países.

\section{Familia Cervidae Subfamilia Odocoileinae}

62. Odocoileus virginianus (Zimmermann, 1780). Subespecie en Guanajuato: Odocoileus virginianus mexicanus (Gmelin, 1788). Existe un ejemplar del municipio de Guanajuato (USNMA 16473), colectado por Dugès y determinado como O. v. mexicanus. Hall (1981) indica que esta es la subespecie que ocuparía la mayor parte del estado; sin embargo, de acuerdo con otras fuentes analizadas por Mandujano et al. (2010) existe la posibilidad de que pudieran hallarse presentes otras como O. v. miquihuanensis en el norte-noreste y $O$. v. sinaloae en la región del Bajío. Morfométricamente no puede confirmarse la identidad subespecífica del ejemplar del municipio de Guanajuato alojado en MADUG-MA, pues se trata del cráneo de una hembra joven. Algunos registros fotográficos recientes obtenidos en los municipios de Xichú (IBUNAM:CFB:FB 1239; Sánchez-Cordero et al. 2011; Iglesias et al. 2012) y Victoria (IBUNAM:CFB:FB 1870, 1903, 2073, 2075, entre otros; Charre-Medellín et al. 2012b), tampoco permiten determinar la subespecie. Por otra parte, la futura confirmación de las subespecies presentes en Guanajuato quizá deba basarse en evidencia molecular, sobre todo proveniente de ejemplares genuinamente autóctonos, pues no puede descartarse la introducción de pie de cría de muy distintas subespecies, ajenas al centro del país, por ejemplo en Unidades de Manejo y Aprovechamiento Sustentable para la Conservación de la Vida Silvestre (UMA), especialmente aquellas que operan con poblaciones animales en vida libre. Estado de conservación: Lista Roja IUCN, especie de menor preocupación (Least Concern); CITES, todas las subespecies de México quedan excluidas de los Apéndices; SEMARNAT-EP-2014, incluida en la lista, se trata de una especie focal para Guanajuato, con gran potencial como motivo para la protección de distintos tipos de hábitat y la permanencia de poblaciones sanas, con grandes beneficios para muchas otras especies silvestres y para intereses de aprovechamiento, siempre que se manejen las subespecies locales y no pie de cría de subespecies ajenas a la entidad.

\section{Familia Antilocapridae}

63.*Antilocapra americana (Ord, 1815). Subespecie en Guanajuato: Antilocapra americana mexicana Merriam, 1901. Esta fue la subespecie que habitó territorio de Guanajuato al parecer hasta el Siglo XVII. Se le conoce gracias a registros históricos para el área entre Zacatecas e Hidalgo (de Torquemada 1615, Clavijero 1780).Un ejercicio de simulación de distribución potencial (Ceballos et al. 2006) también ubica al menos el NE de Guanajuato (el área de San Luis de la Paz-Victoria) como parte del ambiente propicio para la especie, que en el pasado fue continuo hacia la extensa Altiplanicie Mexicana. También se ha informado de restos arqueológicos de esta especie, del municipio de Abasolo (Álvarez y Ocaña 1999). Estado de conservación: Lista Roja IUCN, especie de 
menor preocupación (Least Concern); NOM-059, en Peligro (P); SEMARNAT-EP-2014, enlistada (aunque para Guanajuato sólo tendría sentido manejarla mediante restauración previa del hábitat y reintroducción).

\section{ORDEN CHIROPTERA \\ Familia Phyllostomidae \\ Subfamilia Macrotinae}

64. Macrotus waterhousii Gray, 1843. Subespecie en Guanajuato: Macrotus waterhousii bulleri $\mathrm{H}$. Allen, 1890. Hasta el presente sólo se conoce de los municipios de Santa Catarina y Tierra Blanca (CNMA; Sánchez et al. 2009). Estado de conservación: Lista Roja IUCN, especie de menor preocupación (Least Concern).

\section{Subfamilia Desmodontinae}

65. Desmodus rotundus (E. Geoffroy Saint-Hilaire, 1810). Subespecie en Guanajuato: Desmodus rotundus murinus Wagner, 1840. Es la única subespecie que existe en México. Los ejemplares conocidos de Guanajuato proceden de los municipios de San Luis de la Paz (CNMA, Sánchez et al. 2009; ENCB-IPN, Elizalde-Arellano et al. 2010); San Miguel de Allende, Victoria y Xichú (CNMA, Sánchez et al. 2009), San Diego de la Unión y Santa Catarina (ENCB-IPN; Elizalde-Arellano et al. 2010). Estado de conservación: Lista Roja IUCN, especie de menor preocupación (Least Concern).

66. Diphylla ecaudata Spix, 1823. Subespecie en Guanajuato: La especie se considera monotípica. Solo se conoce del extremo oriental del estado de Guanajuato; los ejemplares y registros fotográficos existentes son de los municipios de Victoria y Xichú (CNMA; Magaña-Cota et al. 2010). Estado de conservación: Lista Roja IUCN, especie de menor preocupación (Least Concern).

\section{Subfamilia Phyllostominae Tribu Glossophagini}

67. Anoura geoffroyi Gray, 1838. Subespecie en Guanajuato: Anoura geoffroyi lasiopyga (Peters, 1868). Esta es la única subespecie que existe en México. Los ejemplares conocidos para Guanajuato son de los municipios de Guanajuato (USNM A49356, colectado por A. Dugès), Acámbaro (ENCB-IPN), Cuerámaro (MADUG-MA; Sánchez y Magaña-Cota 2008) y Xichú (CNMA; Sánchez et al. 2009). Estado de conservación: Lista Roja IUCN, especie de menor preocupación (Least Concern).

68. Choeronycteris mexicana Tschudi, 1844. Subespecie en Guanajuato: La especie es monotípica. Los ejemplares del estado son de los municipios de Acámbaro (KU 98884 y 98885, 99103-99105); Cortázar, Guanajuato, Manuel Doblado, San Miguel de Allende y Xichú (CNMA; Sánchez y Magaña-Cota 2008). Lozoya Gloria y Uriarte Garzón (2012) la citan para Irapuato. Estado de conservación: Lista Roja IUCN, especie casi amenazada (Near Threatened). NOM-059, Amenazada (A). 
69. Glossophaga soricina (Pallas, 1766). Subespecie en Guanajuato: Glossophaga soricina handleyi Webster y Jones, 1980. Es la única subespecie en México continental. Existen ejemplares de los municipios de San Luis de la Paz (ENCB-IPN), Santa Catarina y Xichú (CNMA; Sánchez et al. 2009). Estado de conservación: Lista Roja IUCN, especie de menor preocupación (Least Concern).

70. Leptonycteris nivalis (de Saussure, 1860). Subespecie en Guanajuato: La especie es monotípica. Se conocen ejemplares de los municipios de Guanajuato (MADUG-MA; Sánchez y Magaña-Cota 2008) y San Luis de la Paz (ENCB-IPN). Estado de conservación: Lista Roja IUCN, especie en peligro (Endangered A2c); NOM-059, amenazada (A); SEMARNAT-EP-2014, incluida en el listado, es una especie focal excelente para promover la conservación de distintos ambientes naturales en Guanajuato, especialmente porque aún está en riesgo (véase la nota correspondiente a la otra especie del género, $L$. yerbabuenae, con la cual puede trabajarse en forma sinérgica en la entidad).

71. Leptonycteris yerbabuenae Martínez y Villa-Ramírez, 1940. Subespecie en Guanajuato: La especie es monotípica. Ramírez-Pulido et al. (2005) la refieren como $L$. curasoae yerbabuenae pero Simmons y Wetterer (2002), Wilson y Reeder (2005) y Cole y Wilson (2006) habían restringido curasoae a Suramérica, por lo que L. yerbabuenae es la especie presente en México. Los ejemplares que la documentan para Guanajuato provienen de los municipios de San Luis de la Paz y Santa Catarina (ENCB-IPN; ElizaldeArellano et al. 2010). Estado de conservación: Lista Roja IUCN, especie vulnerable (Vulnerable A2c); NOM-059, amenazada (A) mencionada como Leptonycteris curasoae (en 2013 se hizo el anuncio de que en vista de la mejoría de sus poblaciones será retirada de la NOM-059; R. Medellin, com. pers.); SEMARNAT-EP-2014, incluida en la lista, lo que ofrece una oportunidad adicional para la conservación y recuperación de matorrales xerófilos y selvas subtropicales en Guanajuato, centrando acciones respecto a los requerimientos ambientales de esta especie polinívoro-nectarívoro-insectívora en vías de recuperación y los similares de su especie hermana $L$. nivalis, que aún se halla en riesgo.

\section{Tribu Stenodermatini}

72. Artibeus jamaicensis Leach, 1821. Subespecie en Guanajuato: Artibeus jamaicensis yucatanicus J. A. Allen, 1904. Sólo se ha registrado en el extremo noreste del estado, en el municipio de San Luis de la Paz (ENCB-IPN; Elizalde-Arellano et al. 2010). Estado de conservación: Lista Roja IUCN, especie de menor preocupación (Least Concern).

73. Artibeus lituratus (Olfers, 1818). Subespecie en Guanajuato: Artibeus lituratus palmarum J. A. Allen y Chapman, 1897. Esta es la única subespecie en México. Para Guanajuato sólo existen registros de Xichú (CNMA; Sánchez et al.2009). Estado de conservación: Lista Roja IUCN, especie de menor preocupación (Least Concern). 
74. Dermanura azteca (Andersen, 1906). Subespecie en Guanajuato: Dermanura azteca azteca (Andersen, 1906). Es la única subespecie presente en México. Sólo se conoce del noreste del estado, en el municipio de San Luis de la Paz (ENCB-IPN; Elizalde-Arellano et al. 2010). Estado de conservación: Lista Roja IUCN, especie de menor preocupación (Least Concern) mencionada como Artibeus aztecus.

75. Sturnira hondurensis Goodwin, 1940. Subespecie en Guanajuato: Se trata de una especie hasta el momento monotípica. Se había registrado de Guanajuato como Sturnira ludovici ludovici Anthony, 1924, pero hoy se considera que S. ludovici está confinada al norte de América del Sur (Colombia-Venezuela y sus alrededores; Velazco y Patterson, 2013), por lo que el taxón presente en México es $S$. hondurensis. De Guanajuato existen ejemplares de los municipios de Acámbaro (ENCB-IPN), Tierra Blanca, Santa Catarina y Xichú (CNMA; Sánchez et al. 2009). Estado de conservación: Lista Roja IUCN especie de menor preocupación (Least Concern) como S. ludovici, pero tendría que reevaluarse en su actual categoría taxonómica.

76. Sturnira parvidens Goldman, 1917. Subespecie en Guanajuato: Es una especie monotípica. Antes registrada del estado como Sturnira lilium parvidens Goldman, 1917, ha sido elevada a especie por Velazco y Patterson (2013) diferenciándola de S. lilium, la cual queda restringida al Ilamado escudo brasileño en América del Sur. De Guanajuato existen ejemplares de los municipios de San Luis de la Paz (ENCB-IPN); también de Santa Catarina-Tierra Blanca y Xichú (CNMA; Sánchez et al. 2009). Estado de conservación: Lista Roja IUCN, especie de menor preocupación (Least Concern) como S. lilium; probablemente tendrá que reevaluarse considerando el cambio taxonómico.

\section{Familia Mormoopidae}

77. Mormoops megalophylla (Peters, 1864). Subespecie en Guanajuato: M. megalophylla megalophylla (Peters, 1864). Es la única subespecie presente en México (Hall 1981). Se conocen especímenes de los municipios de Guanajuato (CNMA, Sánchez et al. 2008; USNM 102419) y de San Luis de la Paz (ENCB-IPN). También se ha registrado de los municipios de Tierra Blanca, Victoria y Santa Catarina (CNMA; Sánchez et al. 2009). Estado de conservación: Lista Roja IUCN, especie de menor preocupación (Least Concern).

78. Pteronotus parnellii (Gray, 1843). Subespecie en Guanajuato: P. parnellii mexicanus (Miller, 1902). Existe un ejemplar colectado en el municipio de Xichú (CNMA; Sánchez et al. 2009) y otros de San Luis de la Paz (ENCB-IPN). Estado de conservación: Lista Roja IUCN, especie de menor preocupación (Least Concern).

\section{Familia Molossidae Subfamilia Molossinae}

79. Promops centralis Thomas, 1915. Subespecie en Guanajuato: Promops centralis centralis Thomas, 1915. Esta subespecie es la única conocida de México. Sólo se ha encontrado en el municipio de Guanajuato (MADUG-MA 181; Sánchez y Magaña-Cota 
2008). Estado de conservación: Lista Roja IUCN, especie de menor preocupación (Least Concern).

\section{Subfamilia Tadarinae}

80. Tadarida brasiliensis (I. Geoffroy Saint-Hilaire, 1824). Subespecie en Guanajuato: Tadarida brasiliensis mexicana (de Saussure, 1860). Esta subespecie tiene amplia distribución en el país. Existen ejemplares de los municipios de Acámbaro (USNM 52258); Guanajuato (USNM 13125, 13534, 15170, 62459-62467 y 62472); varios ejemplares en CNMA reportados por Sánchez y Magaña-Cota 2008; otros ejemplares también se relacionan con este municipio: TCWC 29367-29381); Celaya, Dolores Hidalgo, Manuel Doblado, Cortázar-Jaral del Progreso, Santa Catarina y Victoria-Tierra Blanca (CNMA; Sánchez et al. 2009) y San Luis de la Paz (ENCB-IPN). Lozoya Gloria y Uriarte Garzón (2012) la registraron para Irapuato. Estado de conservación: Lista Roja IUCN, especie de menor preocupación (Least Concern).

\section{Familia Vespertilionidae Subfamilia Myotinae}

81. Myotis californicus (Audubon \& Bachman, 1842). Subespecie en Guanajuato: Myotis californicus mexicanus (de Saussure, 1860). Se conocen ejemplares de los municipios de Guanajuato (MADUG-MA; Sánchez y Magaña-Cota 2008) y de San Luis de la Paz (CNMA; Sánchez et al. 2009). Estado de conservación: Lista Roja IUCN, especie de menor preocupación (Least Concern).

82. Myotis thysanodes Miller, 1897. Subespecie en Guanajuato: Myotis thysanodes thysanodes Miller, 1897. Se ha registrado de los municipios de San Felipe, Ocampo, San Luis de la Paz y Victoria (ejemplares en CNMA; Sánchez et al. 2009). Estado de conservación: Lista Roja IUCN, especie de menor preocupación (Least Concern).

83. Myotis velifer (J. A. Allen, 1890). Subespecie en Guanajuato: Myotis velifer velifer (J. A. Allen, 1890). Existen ejemplares de los municipios de Acámbaro (KU 62365; ENCBIPN), Cuerámaro (MADUG-MA; Sánchez y Magaña-Cota 2008); Guanajuato (USNM 15144-15168; CNMA; Sánchez y Magaña-Cota 2008). Estado de conservación: Lista Roja IUCN, especie de menor preocupación (Least Concern).

84. Myotis yumanensis (H. Allen, 1864). Subespecie en Guanajuato: Myotis yumanensis lutosus Miller y G. M. Allen, 1928. Se conocen registros de los municipios de Guanajuato (CNMA 4813; MADUG-MA), Manuel Doblado (CNMA 23818), Pénjamo (USNM 13122 y 144529), San Luis de la Paz (CNMA 21058-21060 y 21063; Sánchez y Magaña-Cota 2008; y ENCB-IPN 42989). Estado de conservación: Lista Roja IUCN, especie de menor preocupación (Least Concern). 


\section{Subfamilia Vespertilioninae \\ Tribu Nycticeiini}

85. Baeodon alleni Thomas, 1892. Subespecie en Guanajuato: La especie es monotípica. Existen ejemplares de los municipios de Guanajuato (MADUG-MA; Sánchez y MagañaCota 2008), Manuel Doblado y Santa Catarina-Tierra Blanca (CNMA; Sánchez et al. 2009) y de San Luis de la Paz (ENCB-IPN 42998-43002). Estado de conservación: Lista Roja IUCN, especie de menor preocupación (Least Concern) mencionada como Rhogeessa alleni.

\section{Tribu Plecotini}

86. Corynorhinus mexicanus G. M. Allen, 1916. Subespecie en Guanajuato: La especie es Monotípica. Hall (1981) la menciona del municipio de Guanajuato. Existen otros especímenes de Guanajuato (USNM81643, 81644, 81646-81656, 81658, 81661 y 81662) y MADUG-MA; Sánchez y Magaña-Cota 2008) y de Coroneo (CNMA 23813). Estado de conservación: Lista Roja IUCN, especie casi amenazada (Near Threatened).

87. Corynorhinus townsendii (Cooper, 1837). Subespecie en Guanajuato: Corynorhinus townsendii australis Handley, 1955. Esta subespecie tiene amplia distribución en el país. Para Guanajuato existen ejemplares de los municipios de Coroneo (CNMA 23812), Cortázar (CNMA 22597) y San Miguel de Allende (CNMA 23811); Guanajuato (USNM 81645, 81657, 81659 y 81660), MADUG-MA; Sánchez y Magaña-Cota 2008) y San Luis de la Paz (ENCB-IPN). Cuatro ejemplares en el USNM (22217, 22218, 60379 y 60380), colectados por Pierre Louis Jouy, están rotulados como "Charcas, Guanajuato" y fechados en 1891; probablemente la localidad correcta sea Charcas, San Luis Potosí, pues este naturalista trabajó en San Luis Potosí durante 1891 y no en Guanajuato (Jouy 1893). Estado de conservación: Lista Roja IUCN, especie de menor preocupación (Least Concern).

88. Idionycteris phyllotis (G. M. Allen, 1916). Subespecie en Guanajuato: Idionycteris phyllotis phyllotis (G. M. Allen, 1916). Se han encontrado ejemplares en Santa CatarinaTierra Blanca (CNMA; Sánchez y Magaña-Cota 2008). Estado de conservación: Lista Roja IUCN, especie de menor preocupación (Least Concern).

\section{Tribu Eptesicini}

89. Eptesicus fuscus (Palisot de Beauvois, 1796). Subespecie en Guanajuato: Eptesicus fuscus miradorensis ( $\mathrm{H}$. Allen, 1866). Se conocen ejemplares obtenidos en los municipios de Guanajuato (MADUG-MA; USNM 85416, Sánchez y Magaña-Cota 2008), San Luis de la Paz (ENCB-IPN) y Xichú (CNMA 21370). Estado de conservación: Lista Roja IUCN, especie de menor preocupación (Least Concern). 


\section{Tribu Lasiurini}

90. Lasiurus blossevillii (Lesson \& Garnot, 1826). Subespecie en Guanajuato: Lasiurus blossevillii teliotis ( $\mathrm{H}$. Allen, 1891). Se conocen ejemplares de los municipios de Guanajuato (USNM 12662 y 12663), Irapuato y Cuerámaro (MADUG-MA; Sánchez y Magaña-Cota 2008; Magaña-Cota 2008); también de Coroneo, Santa Catarina-Tierra Blanca y Tarimoro (CNMA; Sánchez et al. 2009), además de Victoria (CNMA 2103821042). Estado de conservación: Lista Roja IUCN, especie de menor preocupación (Least Concern).

91. Lasiurus cinereus (Palisot de Beauvois, 1796). Subespecie en Guanajuato: Lasiurus cinereus cinereus (Palisot de Beauvois, 1796). Esta es la única subespecie presente en México. Existen ejemplares de los municipios de Acámbaro (ENCB-IPN); Guanajuato (USNM13215; Sánchez y Magaña-Cota 2008), Coroneo, San Felipe, Victoria y Xichú (CNMA; Sánchez et al. 2009) y de San Luis de la Paz (ENCB-IPN). Estado de conservación: Lista Roja IUCN, especie de menor preocupación (Least Concern).

\section{Tribu Pipistrellini}

92. Parastrellus hesperus (H. Allen, 1864). Subespecie en Guanajuato: Parastrellus hesperus maximus (Hatfield, 1936). Hasta el momento se conoce de los municipios de Cuerámaro (Sánchez y Magaña-Cota 2008), Xichú (CNMA; Sánchez et al. 2009) y San Luis de la Paz (ENCB-IPN). Estado de conservación: Lista Roja IUCN, especie de menor preocupación (Least Concern) mencionada como Pipistrellus hesperus.

\section{Subfamilia Antrozoinae}

93. Antrozous pallidus (Le Conte, 1856). Subespecie en Guanajuato: Antrozous pallidus pallidus (Le Conte, 1856). Esta subespecie está ampliamente distribuida en la Altiplanicie Mexicana. En Guanajuato se le ha encontrado en el noreste del estado, en el municipio de San Diego de la Unión (ENCB-IPN 43005; Elizalde-Arellano et al. 2010). Estado de conservación: Lista Roja IUCN, especie de menor preocupación (Least Concern).

Riqueza y composición de la mastofauna de Guanajuato. Las 93 especies de mamíferos silvestres de Guanajuato se distribuyen en 20 familias pertenecientes a ocho órdenes zoológicos, como se muestra en la Tabla 1.

Hasta donde indica la información actual para Guanajuato, al nivel de familias los carnívoros muestran mayor riqueza con cinco, seguidos por los roedores y quirópteros.

Sin embargo, al nivel de especies el mayor número corresponde a los roedores, luego a los quirópteros y carnívoros. La Figura 1 muestra la riqueza de las especies de mamíferos de Guanajuato por familias; los roedores de la familia Cricetidae muestran el mayor número de especies (18, si se consideran como de una especie los registros asignables al complejo taxonómico S. hispidus de Henson y Bradley (2009), pero que en realidad podrían pertenecer a dos o más especies). Les siguen los murciélagos de 
las familias Vespertilionidae y Phyllostomidae (13 especies cada una). El resto de las familias son menos ricas en especies: las ratas de abazones (Heteromyidae) cuentan con ocho, las ardillas (Sciuridae) con seis y los gatos silvestres (Felidae) con cinco. Otras 14 familias de mamíferos cuentan con menos de cinco especies conocidas en el estado.

Cobertura geográfica del muestreo en Guanajuato hasta 2014. Hasta 2014 se cuenta con registros de mamíferos silvestres para 30 (65.22\%) de los 46 municipios de Guanajuato. La Figura 2 muestra una primera evaluación gruesa de la cobertura de muestreo de mamíferos silvestres en Guanajuato por municipios, con base en los registros conocidos. Sólo 13 municipios cuentan con información para más de 10 especies y de ellos, únicamente cinco cuentan con más de 20 especies registradas. Aún en los municipios mejor trabajados, como Guanajuato y San Luis de la Paz, es esperable que exista una mayor riqueza de especies, pues el número de localidades muestreadas no resulta suficientemente representativo del área, ni de todos los ambientes que existen en esas demarcaciones.

\begin{tabular}{|c|c|c|c|}
\hline \multirow{10}{*}{$\begin{array}{l}\text { Tabla 1. Riqueza de } \\
\text { especies de mamíferos } \\
\text { de Guanajuato. }\end{array}$} & ORDEN & No. de familias & No. de especies \\
\hline & Didelphimorphia & 1 & 2 \\
\hline & Cingulata & 1 & 1 \\
\hline & Lagomorpha & 1 & 4 \\
\hline & Rodentia & 4 & 34 \\
\hline & Carnivora & 5 & 17 \\
\hline & Soricomorpha & 1 & 2 \\
\hline & Chiroptera & 4 & 30 \\
\hline & Artiodactyla & 3 & 3 \\
\hline & TOTAL & 20 & 93 \\
\hline
\end{tabular}

A primera vista, en el mapa podría parecer que la cobertura de muestreo del estado es relativamente buena, lo que obedece a la escala gruesa, pero si se observa en la Figura 3 la riqueza de registros por municipio, se apreciará que muy pocas demarcaciones cuentan con un muestreo realmente suficiente. Aun cuando no fue propósito del presente estudio revisar la cobertura detallada de localidades de muestreo a ese nivel, un ejemplo ilustra la situación en general deficitaria: uno de los municipios con muestreo mejor planeado y más intenso en los años recientes es San Luis de la Paz, a pesar de lo cual las localidades visitadas no exceden 25 (Sánchez y Magaña-Cota 2008; Sánchez et al. 2009; Elizalde-Arellano et al. 2010; Magaña-Cota et al. 2012; Sánchez et al. 2014).

Además muchas de ellas se encuentran muy cercanas entre sí, lo que deja amplias áreas y ambientes del municipio aún sin muestrear. Tomando San Luis de la Paz como referente, es claro que la situación del muestreo en otros municipios es aún menos representativa de sus respectivos territorios. La cartografía de localidades particulares de registro, actualmente en proceso, permitirá percibir con mayor claridad los grandes vacíos geográficos del registro de mamíferos en los distintos municipios de Guanajuato.

Los 16 municipios para los que se carece de registros son Apaseo el Alto, Apaseo el Grande, Comonfort, Doctor Mora, Huanímaro, Jerécuaro, Pueblo Nuevo, Purísima del Rincón, Romita, San Francisco del Rincón, Santa Cruz de Juventino Rosas, Santiago 


\section{Riqueza relativa de especies de mamíferos en Guanajuato}





Figura 1. Composición de la mastofauna de Guanajuato, en función del número de especies por familias zoológicas.

Maravatío, Tarandacuao, Uriangato, Valle de Santiago y Villagrán. En su conjunto representan una tercera parte del total de 46 municipalidades; en cuanto a superficie se trata de 5,633 $\mathrm{km}^{2}$ aún no muestreados, que significan el $18.40 \%$ de la extensión del estado. Fisiográficamente, las ausencias de registros más notorias corresponden a la Cuenca Alta del Río Santa María, en el extremo norte del estado; la confluencia de las Cuencas Temascatío-Guanajuato-Silao-La Laja, justo en el centro del estado; el noreste de la Cuenca del Río Turbio en el oeste de Guanajuato y varias partes de la Cuenca del Río Lerma propiamente dicha, en el extremo sur de la entidad.

La riqueza de registros para las especies en los 30 municipios que cuentan con información se muestra en la Figura 3. De esos municipios muestreados hasta 2012, solamente cinco (16.66 \%) cuentan con registros para más de 20 especies. Para la gran mayoría de ellos la composición de la mastofauna se conoce de manera precaria.

Respecto a la amplitud de distribución conocida para las especies, hasta 2012 solamente 25 especies se habían registrado de más de cinco municipios. Inclusive especies consideradas comunes y de amplia distribución en el centro del país como Peromyscus gratus, P. levipes, P. maniculatus, P. melanophrys, Reithrodontomys fulvescens, Heteromys irroratus y Tadarida brasiliensis sólo cuentan con registros para 12, o cuando más 14, de los 30 municipios muestreados (Figura 4). 
Afinidades geográficas actuales de la mastofauna de Guanajuato. El insuficiente conocimiento de la distribución de las especies en el estado no permite un análisis detallado de afinidades faunísticas; sin embargo es posible ofrecer un primer atisbo al tema. La mayor parte de los taxones presentes en Guanajuato son de amplia distribución en el país, por lo que no resultan informativos en este sentido; pero otros están claramente vinculados con ciertas provincias biogeográficas. Su revisión indica una composición mixta de la mastofauna estatal.

Un considerable número de taxones de Guanajuato tienen clara asociación con la fauna de la Altiplanicie Mexicana: Lepus californicus, Sylvilagus audubonii, Xerospermophilus spilosoma, Neotoma leucodon, Peromyscus eremicus, Chaetodipus eremicus, C. nelsoni, C. hispidus, Dipodomys merriami, D. ordii, D. ornatus, Sigmodon fulviventer, Taxidea taxus, Antrozous pallidus, Idionycteris phyllotis, y en el pasado Antilocapra americana. Otros, actualmente registrados del extremo nororiente de Guanajuato, se relacionan con la fauna de la vertiente del Golfo de México: Leopardus pardalis pardalis, L. wiedii oaxacensis, Herpailurus yagouaroundi cacomitli y Diphylla ecaudata. Otros más se relacionan con la fauna subtropical del Bajío, que pertenece a la parte alta de la vertiente del Pacífico: Leopardus pardalis nelsoni, Tlacuatzin canescens y Oryzomys albiventer. Finalmente, la presencia de Peromyscus hylocetes, ratón endémico del Eje Neovolcánico, en el sur del estado, revela una relación marginal pero inequívoca con la fauna de esa cordillera transversal. Todo esto refleja la ubicación geográfica de Guanajuato, en la cual coinciden partes de estas grandes regiones (Figura 5), cada una con una historia biogeográfica particular.

Figura 2. Cobertura de los registros de mamíferos silvestres en los municipios de Guanajuato, hasta 2014. Las marcas pequeñas indican nueve municipios con apenas cinco especies registradas; las amarillas, ocho municipios con registro de entre 6 y 10 especies; las azules, ocho municipios con entre 11 y 20 especies; y las negras grandes, solo cinco municipios con 21 o más (hasta 45) especies registradas. $\mathrm{Al}$ parecer algunos municipios no cuentan con registros de mamíferos. La figura no refleja el número de localidades muestreadas por municipio. Elaboración propia sobre el mapa base de división municipal de INEGI (2005).

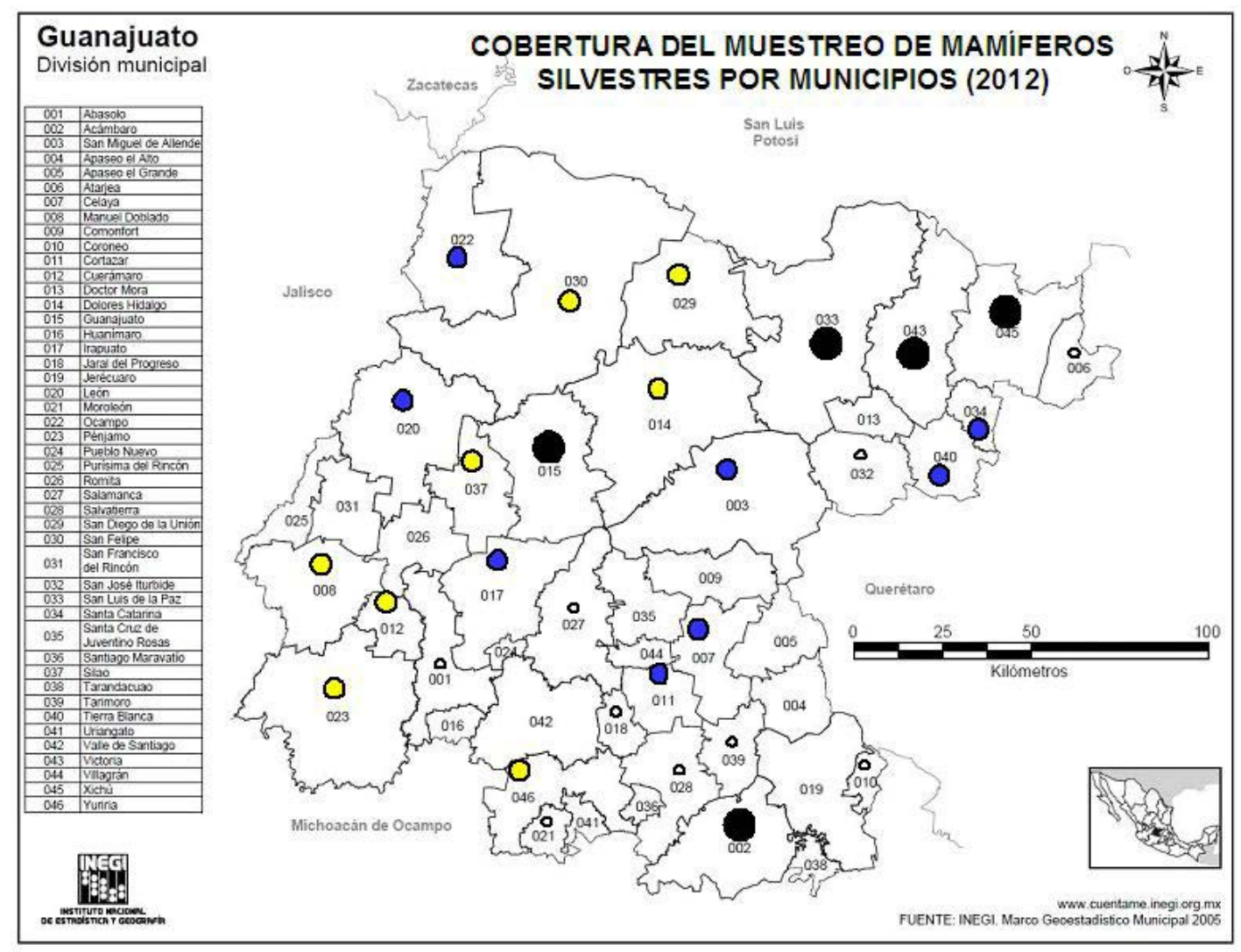


Número de especies registradas

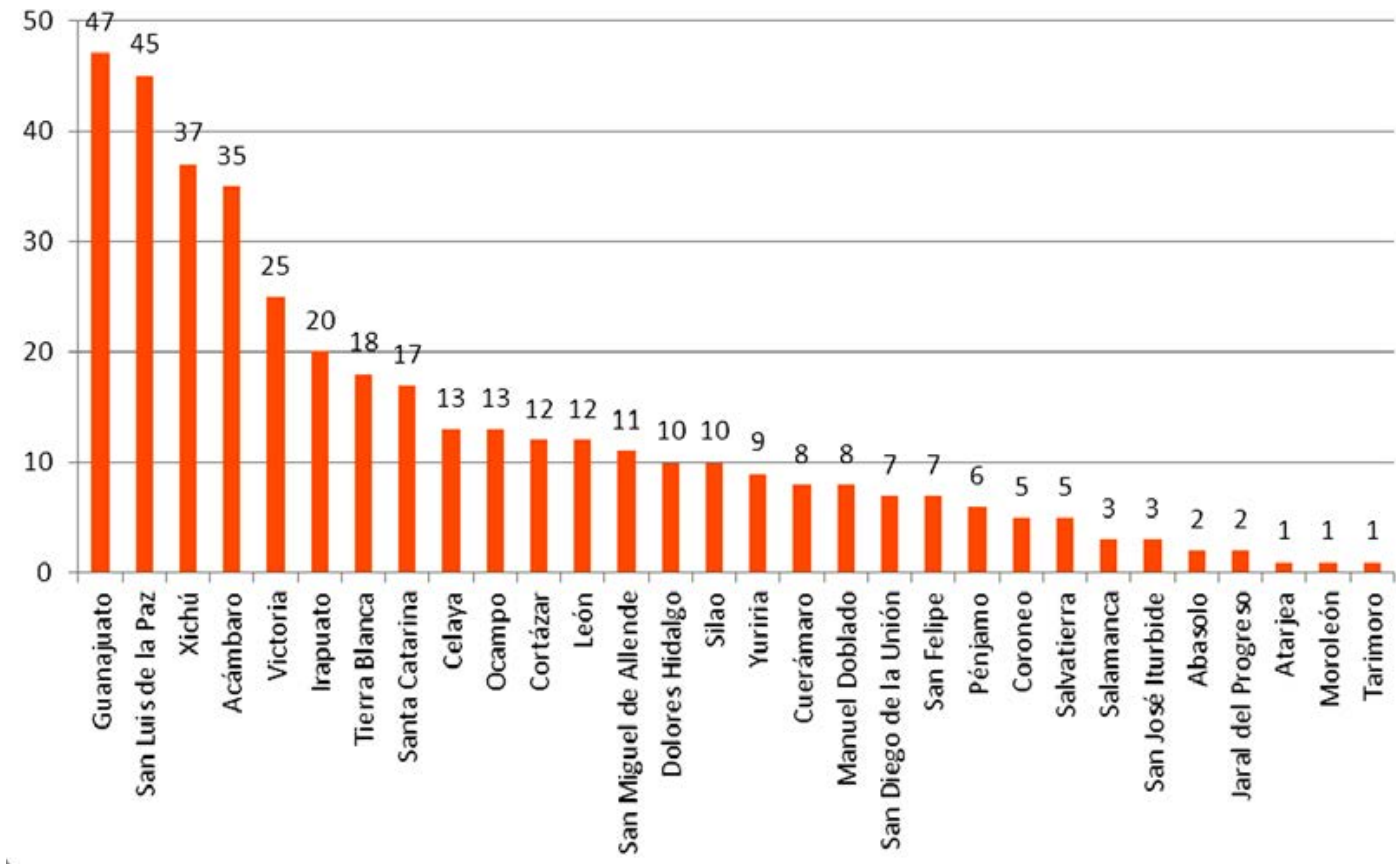

Figura 3. Número de especies registradas para los municipios muestreados hasta 2012. La gráfica no incluye ejemplares anteriormente asignados a Sigmodon hispidus, en espera de que sea posible aclarar la situación taxonómica de las poblaciones del género en la Altiplanicie Mexicana.

Estado de conservación general de la mastofauna. La información actualmente disponible sobre la mastofauna de Guanajuato en su conjunto, en relación con el entorno natural del estado, aún no es suficiente para producir un diagnóstico detallado sobre su estado de conservación. Sánchez et al. (2012) comentaron en forma general que las ANP son la primera línea de protección para la vida silvestre estatal, aunque se requiere que sus programas se intensifiquen, sobre todo en lo que corresponde a monitoreo, vigilancia, restauración, y programas educativos, sociales y económicos encaminados al desarrollo sustentable. El papel de conservación integral de la biodiversidad nativa en los terrenos de las UMA, en general para México y para Guanajuato en particular, es un tanto discutible; sus esfuerzos se han dirigido básicamente a fomentar poblaciones locales de unas cuantas especies de interés económico directo, incluso modificando el ambiente silvestre para favorecerlas, lo cual no necesariamente resulta adecuado en igual medida para otras especies silvestres importantes (Gallina-Tessaro et al. 2009, CONABIO 2012). Por su bajo número de UMA's en vida libre (sólo 16, en una superficie de cerca de 25,300 ha) Guanajuato ocupa apenas el lugar 29 entre las 32 entidades federativas de México (CONABIO 2012). La gran mayoría de las 16 UMA's han mencionado interés o actividad con el venado cola blanca (Odocoileus virginianus) sobre todo con fines de aprovechamiento pero citando a distintas subespecies, ajenas al estado; la introducción de pie de cría de subespecies foráneas, tanto tropicales como de sitios áridos extremos, más que un beneficio sin duda alterará la identidad genética de las poblaciones autóctonas de la especie en Guanajuato, dado que las UMA interesadas son de esquema de producción de venados en vida libre. Por otra parte, Sánchez et al. (2012) destacaron la necesidad de continuar documentando la riqueza y patrones de distribución de poblaciones nativas de mamíferos en el estado, los venados entre otros, y de iniciar -o mejorar si es el caso- el monitoreo científico de poblaciones ya detectadas, para conocer en forma realmente objetiva su condición y tendencia. 
En espera de que se acumule mayor información sobre distintas especies y sus poblaciones, por el momento es posible hacer algunas observaciones respecto a los registros de especies formalmente consideradas en algún grado de riesgo.

Relación entre especies en riesgo y áreas naturales protegidas de Guanajuato. Además del interés académico per se en el estudio de los mamíferos de Guanajuato, una fuerte motivación y urgencia es la de su conservación. Aunque todas las especies son importantes en distintos sentidos, aquellas que han sido diagnosticadas como en riesgo a escala global o nacional requieren atención prioritaria.

En el presente no se cuenta con información directa respecto a la magnitud relativa ni al estado de conservación de poblaciones de especies en riesgo del estado de Guanajuato. Por ello, se consideró útil ubicar al menos cuáles son las ANP del estado que, por su vinculación directa o proximidad a los puntos de registro conocidos para estos mamíferos en riesgo, representan extensiones donde es deseable -y quizá inmediatamente factible- empezar a trabajar para evaluar su situación local y asegurar su permanencia en la entidad.

La Tabla 2 muestra la relación geográfica general entre algunas Áreas Naturales Protegidas (ANP) del estado y 15 especies que se encuentran en riesgo (global conforme a la Lista Roja de la IUCN, nacional respecto a la Norma Oficial NOM059-SEMARNAT-2010, o ambos). En forma precautoria se incluye una especie que recientemente se validó taxonómicamente (Oryzomys albiventer; Carleton y ArroyoCabrales 2009), aunque su estado de riesgo aún no ha sido evaluado a escala global ni nacional. En la tabla se incluyen diez áreas naturales protegidas (ANP) de Guanajuato, con las que esas especies muestran principal vinculación geográfica.

No se incluyeron Canis lupus y Antilocapra americana pues se consideran extirpados del estado (Sánchez et al. 2014), pero se deja abierta la posibilidad en el caso de Lontra

Figura 4. Especies que se han registrado en más de cinco municipios de Guanajuato hasta 2012. Sesenta y siete especies $(72.82 \%)$ se conocen sólo de entre uno y cinco municipios. El estado actual del conocimiento geográfico de la mastofauna es insuficiente para reconocer patrones claros de distribución de las especies. No se incluyen ejemplares anteriormente asignados a Sigmodon hispidus, en congruencia con lo explicado en el pie de la Figura 3.

\section{Número de Municipios}

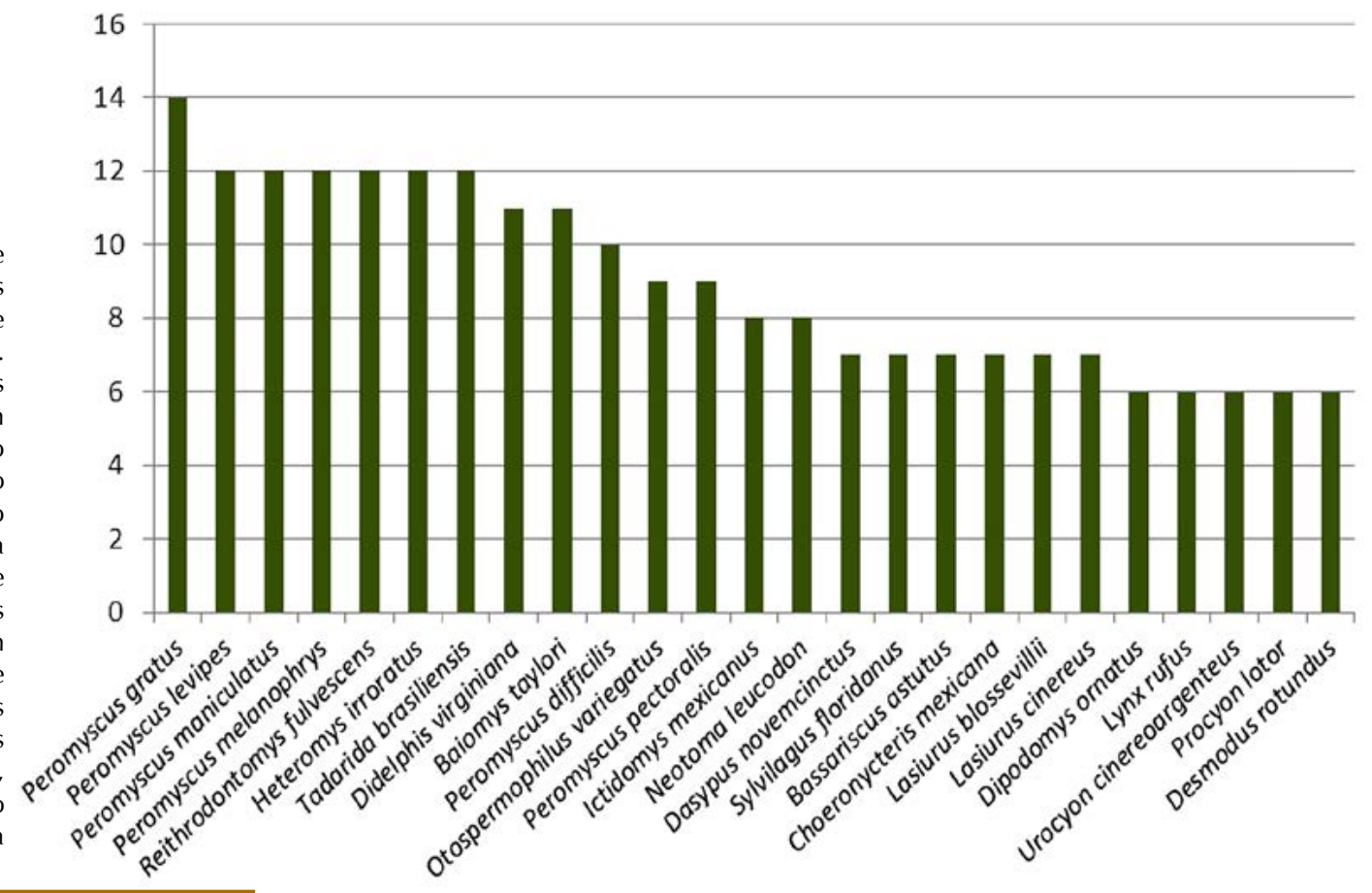


longicaudis, considerando que la Sierra de Pénjamo no se ha explorado suficientemente y que en otros sitios de México se le ha hallado en arroyos y ríos secundarios relativamente en buen estado, aún en áreas donde las corrientes principales se hallan deterioradas en varias formas (Gallo 1997; Sánchez et al. 2007; Monroy-Vilchis y Mundo 2009; CharreMedellín et al. 2011).

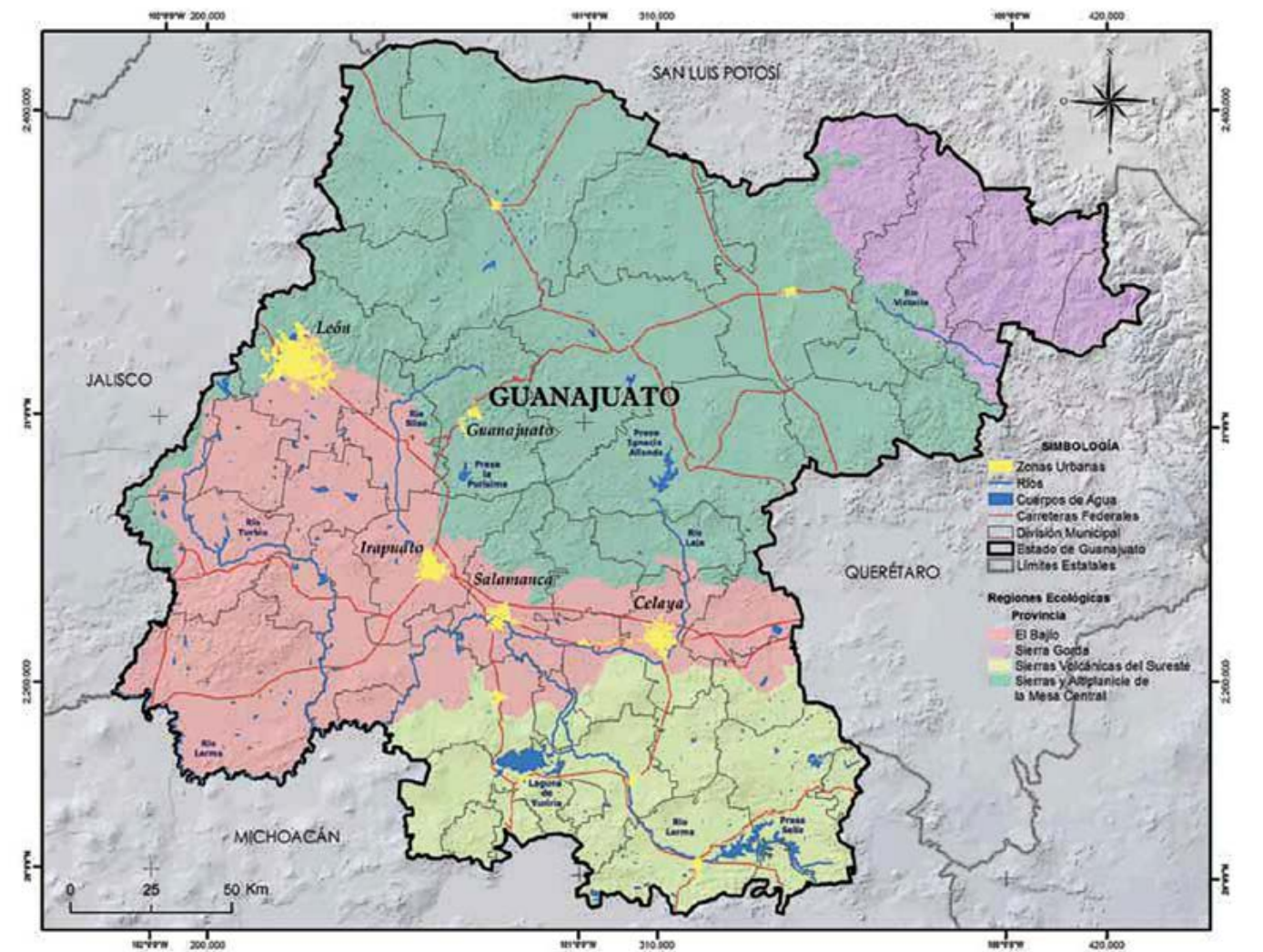

Figura 5. Grandes regiones fisiográficas que inciden en Guanajuato. Como se explica en el texto, algunas especies de mamíferos silvestres son características de cada una de ellas y su presencia refleja la convergencia de distintos procesos biogeográficos y evolutivos en el estado. Fuentes: Bataillon (1988) y Cuevas Carrillo y Zorrilla (2012).

Entre las especies en riesgo presentes en Guanajuato sobresalen tres especies de murciélagos que están incluidas en categorías de riesgo medio o máximo en la Lista Roja de la IUCN y en la NOM-059-SEMARNAT-2010, y una cuarta como casi amenazada en la Lista Roja. Las tres primeras son especies nectarívoro-polinívoro-insectívoras (Leptonycteris nivalis, L. yerbabuenae y Choeronycteris mexicana) cuyo papel ecológico clave en la polinización y dispersión de semillas de plantas de sitios semidesérticos ha sido ampliamente demostrado (Arita y Wilson 1987; Valiente-Banuet et al. 1996; GodínezÁlvarez y Valiente-Banuet 2000; entre otros). Estas especies requieren la conservación de extensiones donde la vegetación original se halle en buen estado, particularmente respecto a la presencia y abundancia de plantas de polinización quiropterófila, como coinciden en señalar esos estudios.

La cuarta es un quiróptero insectívoro (Corynorhinus mexicanus) la cual ha mostrado cierta dependencia de la presencia de cuevas con características de microclima especiales, respecto a su sobrevivencia durante el período invernal y sobre todo a la instalación de colonias de maternidad (López-Wilchis 1989; López-González y TorresMorales 2004). Para el caso de Guanajuato es importante evaluar la presencia de la especie en cavernas naturales, pero también, dada la antigua trayectoria de la entidad en la extracción de minerales, la eventual presencia y posible uso de minas abandonadas por parte de esta especie. 
La liebre Lepus callotis aparece en la Lista Roja de la IUCN como globalmente casi amenazada. Esto puede obedecer tanto a cambios en el uso del suelo como a la eliminación sistemática de ejemplares, sea porque se les considera plaga agrícola o porque se les caza furtivamente (DGVS-SEMARNAT 2010). En Guanajuato la dinámica del cambio de uso de suelo tiene una larga historia y es intensa para muchas actividades, particularmente para fines agrícolas (García et al. 2002; Paredes Melesio et al. 2011), lo que conduce a identificar la necesidad de evaluar el estado de las poblaciones de esta especie en ambientes nativos del estado y, por supuesto, su persistencia o desaparición en áreas dedicadas a la agricultura y la ganadería.

Tabla 2. Relación entre los registros actuales de especies de mamíferos silvestres en alguna situación de riesgo y las áreas naturales protegidas (ANP) de Guanajuato.

\begin{tabular}{|c|c|c|c|c|c|c|c|c|c|c|c|c|}
\hline \multirow[t]{2}{*}{$\begin{array}{l}\text { Especies de Guanajuato en } \\
\text { riesgo }\end{array}$} & \multirow[t]{2}{*}{$\begin{array}{l}\text { Categoría de } \\
\text { riesgo global } \\
\text { (IUCN) }\end{array}$} & \multirow{2}{*}{$\begin{array}{l}\text { Categoría } \\
\text { de riesgo } \\
\text { nacional } \\
\text { (NOM-059) }\end{array}$} & \multicolumn{10}{|c|}{$\begin{array}{l}\text { Áreas naturales protegidas de Guanajuato con las } \\
\text { que se relacionan, en función de las localidades } \\
\text { conocidas hasta } 2012\end{array}$} \\
\hline & & & SG & SL & SP & CG & PA & SA & CE & CS & $\mathrm{CC}$ & CA \\
\hline Leptonycteris nivalis & En Peligro & Amenazada & + & & & & & & + & + & & \\
\hline Leptonycteris yerbabuenae & Vulnerable & Amenazada & + & & & & & & & & & \\
\hline Choeronycteris mexicana & Casi amenazada & Amenazada & + & & + & + & & & & & & + \\
\hline Corynorhinus mexicanus & Casi amenazada & --- & & & & & & & + & + & & \\
\hline Lepus callotis & Casi amenazada & --- & & & & + & & & & & & + \\
\hline Leopardus wiedii & Casi amenazada & En Peligro & + & & & & & & & & & \\
\hline Leopardus pardalis & --- & En peligro & + & & + & & & & & & & \\
\hline Herpailurus yagouaroundi & --- & Amenazada & + & & & & & & & & & \\
\hline Lontra longicaudis & $\begin{array}{l}\text { Deficiente en } \\
\text { datos }\end{array}$ & Amenazada & & & $?$ & & & & & & & \\
\hline Taxidea taxus & --- & Amenazada & & & & & & & & & + & \\
\hline Glaucomys volans & --- & Amenazada & + & & & & & & & & & \\
\hline Sciurus oculatus & --- & $\begin{array}{l}\text { Bajo } \\
\text { Protección } \\
\text { Especial }\end{array}$ & + & + & & & & & + & + & & \\
\hline Dipodomys ornatus & --- & $\begin{array}{l}\text { Bajo } \\
\text { Protección } \\
\text { Especial }\end{array}$ & + & + & & & + & & + & + & & \\
\hline Cratogeomys fumosus & --- & Amenazada & & & & + & + & & + & + & & \\
\hline Oryzomys albiventer ** & No evaluada & No evaluada & & & & & & + & & & & \\
\hline TOTAL DE ESPECIES & & & 9 & 2 & 2 & 3 & 2 & 1 & 5 & 5 & 1 & 2 \\
\hline
\end{tabular}

Las ANP pertenecen a cuatro categorías consideradas por el Instituto de Ecología del Estado de Guanajuato (IEE, 2013): Reserva de la Biosfera: Sierra Gorda de Guanajuato (SG); Área de Uso Sustentable: Sierra de Lobos (SL), Sierra de Pénjamo (SP), Cerros El Culiacán y La Gavia (CG), Peña Alta (PA), Cerro de Arandas (CA) y Sierra de los Agustinos (SA); Reserva de Conservación: Cuenca de la Esperanza (CE); Área de Restauración Ecológica: Cuenca de La Soledad (CS) y Cerro del Cubilete (CC). ${ }^{* *}$ Especie cuyo estado de conservación global y nacional aún no se ha evaluado; en Guanajuato sólo se conoce de la vecindad de SA.

Los félidos manchados (Leopardus pardalis y L. wiedii), el jaguarundi (Herpailurus yagouaroundi), la nutria (Lontra longicaudis) y el tlalcoyote (Taxidea taxus) incluidos en las listas de taxones en riesgo, sobre todo la NOM-059-SEMARNAT-2010 a escala nacional, cuentan con escasa información para Guanajuato y deben protegerse efectivamente sus poblaciones y el hábitat en todas las áreas donde se les ha registrado, sobre todo en las reservas de mayor extensión geográfica, por ejemplo en la Sierra Gorda, la Sierra de Pénjamo y la Sierra de los Agustinos (en espera de conocer su presencia y situación en 
otras cono Pinal de Zamorano, entre varias). En esas áreas, cabe anotar, no solamente es de importancia mantener la vegetación original, sino también condiciones de mínima presencia humana, dado que los felinos y otros carnívoros medianos y grandes son objeto focal de caza furtiva en la Sierra Gorda, para lo cual se pretextan conflictos con actividades humanas (Arroyo-Quiroz y Pérez-Gil 2007).

Por otra parte, se requiere documentar mejor la presencia y distribución de la ardilla planeadora Glaucomys volans en la Sierra Gorda y otros sitios, y revisar el estado que guardan en el estado los bosques de encinos de hojas anchas y tronco nudoso con oquedades, el tipo de hábitat que más favorece a estas ardillas, por ejemplo en bosques con Quercus laurina (Ceballos et al. 2010). Esa especie de encino está presente en la Sierra Gorda como en otros sitios de las sierras de la entidad, entre 2,600 y 2,850 msnm, formando bosques densos perennifolios de hasta 20-25 m de altura, formados casi exclusivamente por Quercus laurina, Q. rugosa (encino avellano) y Q. obtusata (Zamudio Ruiz, 2012). Sin embargo muchos de los sitios que originalmente contenían esta vegetación se han venido talando con fines agrícolas y para producir carbón (Pineda, 1978) tendencia que no puede descartarse todavía. Los encinos de este tipo tienden a volverse más nudosos con la edad y a desarrollar oquedades, de allí la importancia de conservar los bosques antiguos, tanto en favor de G. volans como de otras especies que requieren vegetación densa y con arquitectura compleja. A todo ello hay que agregar que las ardillas en general se perciben, al menos en la Sierra Gorda de Querétaro, como las especies de mamíferos silvestres más perjudiciales para las actividades productivas (21.7\% de una muestra de 171 personas entrevistadas; Arroyo-Quiroz y Pérez-Gil 2007).

Este es un ejemplo de cómo distintos tipos de información resultan más significativos en forma conjunta y, por ello, deben considerarse en esta forma para orientar las políticas públicas de conservación, en este caso de encinares y en particular para especies en riesgo y sensibles como es el caso de G. volans.

En contraste, el caso de otra especie actualmente catalogada como amenazada, la tuza Cratogeomys fumosus, resulta complejo en otro sentido. La NOM-059-SEMARNAT-2010, en sus versiones anteriores, la incluyó considerando su acepción anterior como taxón microendémico de los alrededores de Colima (tal como aparece en Hall 1981:523). Sin embargo, desde hace algunos años se ha demostrado que $C$. fumosus junto con C. neglectus, C. gymnurus, C. zinseri y C. tylorhinus resultan miembros de la misma especie, por lo que hoy todas quedan incluidas en Cratogeomys fumosus (Hafner et al. 2004), especie de amplia distribución, inclusive en terrenos de cultivo. En la actual redacción de la NOM-059-SEMARNAT-2010, el estado de especie amenazada hoy se entendería extendido a todo $C$. fumosus en su amplio sentido taxonómico vigente, por lo que es urgente revisar este caso. Por otro lado, claramente la conservación de las tuzas suele entrar en conflicto con intereses como los agrícolas, por lo que será necesario buscar esquemas que minimicen la contradicción entre ambas perspectivas.

Dipodomys ornatus, taxón que recientemente fue removido de la especie $D$. phillipsii para reconocerlo como especie distinta, es una especie de roedor vinculada primariamente con entornos semiáridos caracterizados por pastos cortos y grupos de nopaleras o matorrales espinosos, entremezclados con porciones de suelo desnudo y se ha dicho que la pérdida de hábitat debida a la agricultura afecta a algunas de sus poblaciones (Álvarez-Castañeda et al. 2008). Aunque la NOM-059-SEMARNAT-2010 
consideraba a la especie $D$. phillipsii en general en la categoría de sujeta a protección especial, en particular asignó a tres de sus subespecies a la categoría de amenazadas; hoy cuando $D$. ornatus se ha segregado de D. phillipsii, debe reevaluarse su situación de conservación como especie distinta, endémica de México, con el método oficial MER (NOM-059-SEMARNAT-2010; Sánchez et al. 2007). Claramente, su situación en Guanajuato necesita evaluarse pronto, sobre todo estimando su grado de resiliencia ante modificaciones agrícolas y ganaderas del suelo, y cambios en la periferia de corredores industriales y centros de población humana.

El tlalcoyote (Taxidea taxus) es uno de los mamíferos menos conocidos del estado y sólo se cuenta con un registro antiguo de su presencia en Silao; municipio donde se encuentra el Área de Restauración Ecológica Cerro del Cubilete. Además de tratar de determinar si el tlalcoyote aún existe en esa área, actualmente con un grado considerable de alteración pero con perspectivas de restauración por parte del gobierno estatal, será necesario intensificar su búsqueda en otras regiones del estado de Guanajuato.

Dos especies se consideran extirpadas de Guanajuato entre la conquista española y el Siglo XIX (Canis lupus y Antilocapra americana; Sánchez et al. 2014) y la probabilidad de redescubrirlas en libertad básicamente se considera nula. Una tercera especie registrada por A. Dugès en el Siglo XIX, la nutria de río (Lontra longicaudis) no se ha vuelto a reportar, pero como se indicó arriba aún puede ser recomendable emprender su búsqueda en riberas de arroyos del sur y suroeste del estado, tributarios de la cuenca del río Lerma, óptimamente con fotografía automática o al menos mediante huellas u otras evidencias indirectas.

Con la información disponible hasta 2014, diez de las 24 ANP de Guanajuato (41.66 $\%$ del total) resultaron relacionadas directa o marginalmente con registros de especies de mamíferos silvestres en riesgo. El conocimiento sobre la distribución geográfica de las especies aún es insuficiente para determinar posibles relaciones con otras áreas protegidas y con extensiones fuera de éstas. Mientras se avanza en nuevos muestreos es recomendable reforzar, dentro de aquellas ANP que se han detectado relacionadas con especies en riesgo, la protección de los hábitats críticos para cada taxón considerando para ello la literatura disponible relativa a su ecología, en términos de lo que se describió arriba sobre el conocimiento de sus requerimientos de cobertura de hábitat, de alimentación, de acceso al agua y de mínima presencia humana. Asimismo es recomendable instalar en esas ANP protocolos de monitoreo sistemático de la presencia y abundancia relativa de esas especies en riesgo, con alcance a los plazos medio y largo.

Hasta donde hoy se sabe, especies como Leptonycteris nivalis, L. yerbabuenae, Choeronycteris mexicana, Leopardus pardalis, L. wiedii, Herpailurus yagouaroundi, Glaucomys volans, Sciurus oculatus y Dipodomys ornatus recibirían cierta protección, al menos nominal, principalmente en el ANP más extensa del estado, la Sierra Gorda, lo cual refleja la importancia de ésta. Conforme a la información actualmente disponible le seguirían la Cuenca de la Esperanza y la Cuenca de la Soledad, con las que se vinculan directamente o a las cuales están próximos registros de Leptonycteris nivalis, Corynorhinus mexicanus, Sciurus oculatus, Dipodomys ornatus y Cratogeomys fumosus.

Por su situación geográfica al este-noreste del estado, y por su aparente y relativa lejanía a influencias humanas intensas, la Reserva de Conservación Pinal de Zamorano 
puede ser otra área clave para la conservación de especies en riesgo en Guanajuato (no sólo de mamíferos sino de muchas otras formas de vida), por lo que resulta urgente su exploración biológica y diagnóstico ambiental a mayor detalle.

El entorno natural del estado de Guanajuato ha sido objeto de alteración desde los primeros poblamientos prehispánicos, pero ésta se tornó notoria y extensa desde el Siglo XVI, cuando en la época colonial se desarrollaron la agricultura extensiva, la ganadería y la minería con gran auge, lo que demandó entre otras cosas la tala de bosques en busca de combustible y empeoró con el advenimiento de la mecanización en el Siglo XIX; luego se tornó prácticamente irreversible con el establecimiento de grandes extensiones de agricultura tecnificada de riego y corredores industriales en los Siglos XIX y XX, lo que ha dejado cada vez menos espacios para la vida silvestre (Almanza y Juárez 2012).

Como se aprecia en la Figura 6, el uso del suelo en Guanajuato es hoy sumamente intenso y extenso, por lo que las ANP (Figura 7) resaltan como la opción más viable para la conservación de mamíferos silvestres, sin ignorar que poblaciones de ciertas especies -las más tolerantes- han conseguido sobrevivir en áreas alteradas. Salvo la Reserva de la Biosfera Sierra Gorda de Guanajuato (con 236,882 ha y única ANP federal en el estado, al noreste) el resto son de carácter estatal y, por la definición de propósito de sus categorías, probablemente podrían colocarse en orden decreciente de estado de conservación del ambiente nativo como sigue: Reservas de Conservación (2, Pinal de Zamorano al sur de la Sierra Gorda y Cuenca de La Esperanza, esta última de pequeña extensión y muy cerca de la Ciudad de Guanajuato), Áreas de Uso Sustentable (11, dos de ellas relativamente extensas, Sierra de Lobos en el noroeste, en la vecindad de la ciudad de León y la Sierra de Pénjamo, al occidente del estado); Áreas de Restauración Ecológica (5); Monumento Natural (1) y Parques Ecológicos (4). En la Figura 7 se señalan las ANP relacionadas con registros de especies en riesgo mencionadas en la Tabla 2.

En general, para todas las especies en riesgo de Guanajuato se estima necesario, así como urgente, detectar poblaciones relevantes dentro y fuera de las áreas protegidas, para diagnosticar su situación actual, conocer su trayectoria y con ello proceder a diseñar las intervenciones necesarias para su conservación.

Un propósito importante de la conservación es que no solo debe atenderse a las especies en riesgo y en relación con ANP, sino también mantener las especies comunes y abundantes en esa condición en todo el territorio posible. Por ello es importante que la información sobre cada grupo biológico (en este caso los mamíferos) se contraste también con aquella relativa al entorno silvestre no protegido, a fin de encontrar opciones de uso sustentable para éste y para las especies que aún contiene, estén en riesgo o no. A fin de cuentas las estrategias de conservación pueden ser globales o generales, sin embargo las acciones deben enmarcarse en las situaciones particulares.

En este sentido puede y debe hacerse uso del reciente acuerdo por el que se dan a conocer especies prioritarias para promover y catalizar la conservación en México (SEMARNAT 2014); en este instrumento de política pública se mencionan siete especies presentes en Guanajuato, de las cuales cinco pueden considerarse focales para este propósito, pues el berrendo y el lobo fueron extirpados de Guanajuato hace mucho y la posibilidad actual de reintroducirlos es incierta, dada la situación que guarda la entidad respecto a los ambientes en que habitaron. 
Figura 6. Vegetación y uso del suelo en el estado de Guanajuato para 2004. Puede observarse la gran extensión ocupada por cultivos (color verde más claro); las áreas de mayor industrialización también se ubican en esas extensiones. Aunque no se muestran en este mapa las áreas sujetas a minería, claramente en ellas hay acumulaciones de materiales de jales y otros desechos, antiguos y recientes, potencialmente tóxicos y propensos a lixiviación donde se ejerce esta actividad (Juárez, 2012). Fuente: Instituto de Ecología del Estado de Guanajuato (IEE, 2009).



Taxones sujetos a regulaciones de comercio internacional (CITES). En el presente trabajo no se analiza el tema de comercio con especies silvestres, pero debido a que el estado de riesgo de algunos taxones es tomado como fundamento para las regulaciones internacionales en la materia de la Convención sobre el Comercio Internacional de Especies Amenazadas de Fauna y Flora Silvestres, se hizo referencia al tema. La CITES contribuye a la protección de especies en riesgo mediante la regulación estricta de su comercio internacional. Siete especies registradas para Guanajuato (incluyendo al lobo mexicano, actualmente extirpado del estado) están incluidas en dos distintos Apéndices de la CITES: Apéndice I: Leopardus pardalis, Leopardus wiedii, Herpailurus yagouaroundi y Lontra longicaudis. Apéndice II: Lynx rufus, Puma concolor y Canis lupus.

Cada Apéndice tiene distintos requisitos y procedimientos establecidos por las disposiciones legales y administrativas de México respecto a la CITES. Esto debe tenerse presente en el ejercicio de atribuciones de las autoridades, en casos que involucren el comercio internacional (importación o exportación) de cualquiera de estas especies. No debe olvidarse que algunas disposiciones de la CITES pueden no ser aplicables a ciertas subespecies, o bien, sólo lo son para algunas. 


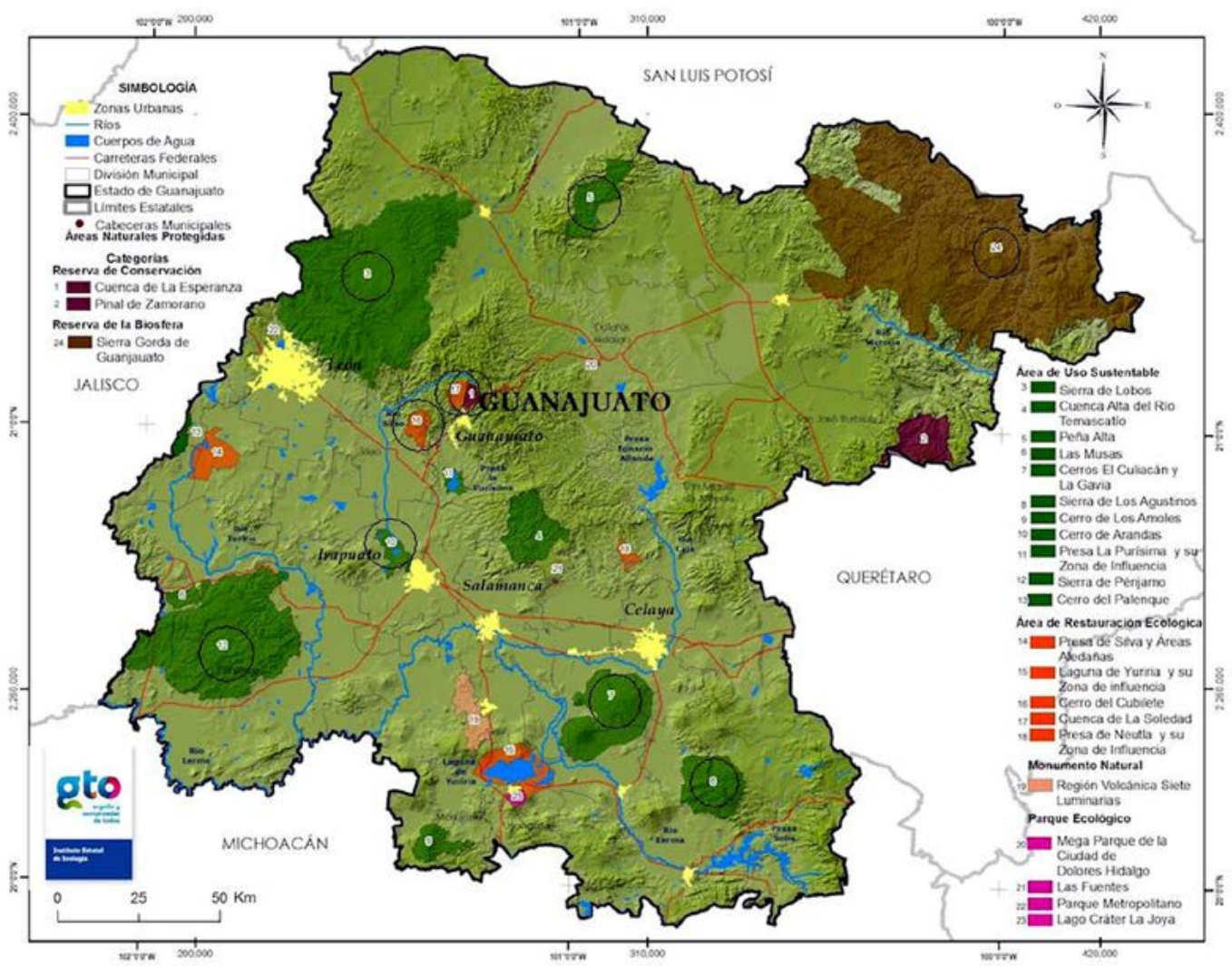

Figura 7. Áreas naturales Protegidas de Guanajuato. Sobre el mapa se indican con círculos aquellas con las cuales se relacionan los actuales registros de especies de mamíferos en riesgo, de modo franco o al menos marginal: Reserva de la Biosfera Sierra Gorda de Guanajuato; Áreas de Uso Sustentable: Sierra de Lobos, Sierra de Pénjamo, Cerros El Culiacán y La Gavia, Peña Alta, Cerro de Arandas y Sierra de los Agustinos; Reserva de Conservación Cuenca de la Esperanza; Áreas de Restauración Ecológica Cuenca de La Soledad y Cerro del Cubilete. La Reserva de Conservación Pinal de Zamorano, al sur de la Sierra Gorda, a pesar de su buen estado de conservación y ubicación estratégica, aún no cuenta con registros de mamíferos silvestres documentados por especímenes o fichas fotográficas formales. En general se requiere mayor cobertura de registros para conocer mejor la situación de los taxones en el estado. Elaboración propia, tomando como base el mapa del Instituto de Ecología del Estado de Guanajuato (IEE 2013).

Al final del Siglo XIX Dugès (1870, 1890 y 1895) había logrado registrar 39 especies de mamíferos en el estado de Guanajuato. Al final del Siglo XX el conocimiento de la mastofauna guanajuatense continuaba limitado, pues por ejemplo Ramírez-Pulido (1986) en su exhaustiva búsqueda a escala nacional, logró recuperar registros sólo para 59 especies. En lo que va del presente siglo, un listado anterior con 87 taxones (Sánchez et al. 2012) ya refleja los hallazgos de varios autores. Recientemente Sánchez et al. (2014) agregaron registros de otros mamíferos no voladores, con lo que se incrementó la lista estatal en seis especies. Hasta 2014 se han registrado 93 especies de mamíferos silvestres del estado de Guanajuato; no obstante, es probable que aún tome algunos años más compilar una lista realmente exhaustiva.

Por lo que se conoce hasta ahora, en Guanajuato el orden Rodentia es el más rico en especies, seguido por Chiroptera y Carnivora. Las 17 especies de Carnivora conocidas del estado representan el $44.73 \%$ de las especies de ese orden presentes en el país, lo cual documenta la importancia de esta fauna estatal, considerando que se trata principalmente de depredadores de tamaño medio a grande. Sin embargo, su conocimiento actual no es suficientemente detallado, por lo que será necesario reunir 
mejores muestras para conocer su situación real en la entidad. El estado general del conocimiento taxonómico sobre el género Sigmodon aún no permite esclarecer la identidad de registros de Guanajuato previamente asignados a S. hispidus.

La cobertura geográfica actual del muestreo de mamíferos silvestres en Guanajuato continúa siendo deficiente. Es altamente probable que una intensificación y mejor distribución del muestreo revele una mayor riqueza y diversidad en la mayoría de los municipios, y quizá algunas especies más para el estado. Las áreas que actualmente están en mayor necesidad de trabajo de campo son el extremo norte del estado; la confluencia de las cuencas centrales, la cuenca del Río Turbio en el oeste y partes de la Cuenca del Río Lerma en el sur.

Pocas especies cuentan con registro en más de 10 municipios (ocho roedores, un murciélago y el tlacuache común); aunque hasta el momento son las que han mostrado una distribución más amplia en Guanajuato, la insuficiencia de las muestras no permite aventurar una idea concluyente.

La mastofauna de Guanajuato se relaciona esencialmente con la de la Altiplanicie Mexicana, muestra un considerable componente de especies tropicales y subtropicales (al oriente hacia la Huasteca y un poco menos notorio al occidente, hacia el Bajío) y finalmente una relación menor con la fauna del Eje Neovolcánico, al sur.

Del total de 93 especies actualmente registradas, menos del 20\% están incluidas en categorías de riesgo global (Lista Roja, IUCN), nacional (NOM-059-SEMARNAT-2010) o en ambas; pero la conservación de los taxones en riesgo en Guanajuato es una indudable prioridad. Los registros actuales de esas especies en riesgo muestran su vinculación con al menos 10 de las 24 ANP del estado como se muestra en la Figura 7 (es decir, con el $37.5 \%$ de éstas). La superficie conjunta de todas las ANP de Guanajuato -una federal y 22 estatales- es de 583,388.15 ha (Guzmán González, 2012) lo que representa apenas el 19\% del territorio estatal que es de 3'060,700 ha (INEGI 2011). Sin embargo, las 10 ANP con las que hasta ahora muestran relación los registros de mamíferos silvestres en riesgo suman un total de 502,909.40 ha, que equivalen al $16.43 \%$ del territorio estatal y representan un panorama alentador para la conservación de las especies en riesgo y otras, a condición de que las actividades humanas en ellas se mantengan realmente ordenadas y al mínimo nivel posible. Aunque la información actual sobre localidades es insuficiente y por ello puede subestimar la relación real de las especies con otras ANP, cuando menos ya permite ubicar algunas áreas en las que es recomendable reforzar en el corto plazo la protección de los hábitats críticos y de las poblaciones locales de esas especies, así como monitorear su permanencia y estado poblacional. La Sierra Gorda de Guanajuato destaca por su importancia para nueve especies en categorías de riesgo, y por su extensión y estado de conservación en realidad para muchas formas de vida silvestre en general, por lo que se requiere revisar con detalle la actual propuesta de zonificación para su plan de manejo (CONANP, 2013; aún en consulta pública en 2014) que incluye polígonos de potencial conflicto, por ejemplo zonas de uso especial -denominación que no excluye la minería- incrustadas en zonas núcleo o adyacentes a éstas. Aunque con mucho menor extensión, también las Cuencas de la Esperanza y La Soledad son relevantes pues se relacionan cada una con cinco especies en riesgo. Con base en la información obtenida para esta contribución, destaca la virtual ausencia de datos formales sobre mamíferos para la Reserva de Conservación de Pinal de Zamorano, 
misma que por su ubicación y estado general del ambiente es una de las más prometedoras para la conservación en general. En las dos áreas de uso sustentable más extensas (Sierra de Lobos y Sierra de Pénjamo) aunque en ellas existen numerosas actividades humanas de impacto elevado, en algunas porciones aún persiste vegetación original, por lo que se estima necesario documentar allí la presencia de mamíferos silvestres. Los otros tipos de ANP de Guanajuato quizá alberguen especies de mamíferos en riesgo además de otras, más tolerantes, por lo que sus planes de manejo necesitan diferenciar claramente las zonas apropiadas para conservar sin actividad humana o minimizarla. La presencia de ciertos taxones de mamíferos, sobre todo los de mayor talla y con requerimientos de buen estado del hábitat natural o depredadores medianos a grandes, puede ser un dato útil si se les considera como especies focales para el diseño o rediseño de sistemas interconectados de reservas (Miller et al., 1999).

En general la mayoría de las especies en riesgo son socialmente percibidas como gratas o importantes, aunque a algunas se les considera con cierta indiferencia o aún peor, se les percibe como nocivas o desagradables (Kellert 1985); la tuza Cratogeomys fumosus se considera tradicionalmente como una especie dañina para la agricultura, por lo que resulta un caso controversial para la conservación. Por otra parte, además la actual inclusión de varias especies como parte de $C$. fumosus sugiere la necesidad de reevaluar el estado de conservación de este taxón conforme al Método de Evaluación de Riesgo (MER) (Sánchez et al. 2007; NOM-059-SEMARNAT-2010). Como ésta, otras especies que recientemente han experimentado cambios taxonómicos, deben reevaluarse.

Dos especies quedaron extirpadas del estado; el berrendo hace casi cuatro siglos y el lobo al parecer hace al menos 150 años. Una tercera, la nutria de río, permanece en situación incierta pero aún no puede descartarse su permanencia en arroyos secundarios que drenan hacia la cuenca del Río Lerma, por ejemplo en la sierra de Pénjamo. Estos tres taxones están considerados en el reciente Acuerdo que establece especies de prioridad nacional como catalizadores de la conservación de hábitat (SEMARNATEP-2014), junto con el venado cola blanca (Odocoileus virginianus), dos murciélagos magueyeros (Leptonycteris nivalis y L. yerbabuenae) y la liebre torda (Lepus callotis). Es oportuno iniciar cuanto antes una prospección de posibilidades respecto a emplear estas especies como focos de atención (en el sentido de Miller et al., 1999) para iniciar programas robustos de conservación de su hábitat en Guanajuato. En el caso de $O$. virginianus, precisamente por su alto interés como especie inductora de interés para la conservación y restauración ecológica, es indispensable erradicar el interés en introducir subespecies foráneas a UMA de vida libre en Guanajuato y fomentar el uso de pie de cría de las subespecies autóctonas. Claramente el caso del lobo y el berrendo representan retos mayores, debido a que sólo podría pensarse en su potencial reintroducción, con todas las complejidades y potenciales conflictos que ello implica; no obstante, las cinco especies restantes pueden representar oportunidades valiosas.

Se estima relevante emprender lo antes posible esfuerzos sistematizados de monitoreo para las especies en riesgo, por lo pronto al menos en aquellas ANP de Guanajuato con las que hasta el momento se les considera vinculadas. También es necesario continuar avanzando en los inventarios, incrementando progresivamente la cobertura geográfica y el grado de detalle de la información, sin excluir la continuidad del esfuerzo de registro de presencia de estas especies pero orientándose cada vez más hacia evaluaciones 
de sus poblaciones y de sus relaciones con el estado actual del entorno. A partir de esa información será posible proponer y construir un sistema básico de monitoreo e información sobre mamíferos silvestres para Guanajuato, tal que permita conocer las poblaciones clave y, en el futuro, sus tendencias. En función de ello se podrá propiciar la instalación y mantenimiento de medidas de conservación adecuadas en el estado. Los félidos ameritan atención especial por su papel como depredadores tope; se requiere mejorar la información sobre su distribución general y situación poblacional en Guanajuato para generar opciones prácticas de conservación. Para el monitoreo de estas especies y de varios mamíferos medianos la fotografía automática, ya ensayada en Guanajuato (Iglesias et al. 2008; Charre-Medellín et al. 2012a y 2012b; CecairaRicoy et al. 2012), ha demostrado ser una técnica adecuada y existe oportunidad para sistematizar progresivamente su aplicación en la entidad.

Siete especies de carnívoros de Guanajuato (ocelote, margay, jaguarundi, lince, puma, nutria y, aunque extirpado, el lobo) están consideradas en los Apéndices de la CITES, por lo que en cualquier evento de comercio internacional con éstas deben atenderse las disposiciones de ley aplicables, consultando previamente a la autoridad científica CITES de México: la Comisión Nacional para el Conocimiento y Uso de la Biodiversidad (CONABIO).

Se espera que la presente sinopsis contribuya en la planeación de etapas subsecuentes de investigación de campo y gabinete, que necesitan mayor cobertura geográfica y de registros en diferentes áreas y ecosistemas del estado. Las bases de datos en preparación y el uso de cartografía digital facilitarán, más adelante, la referencia cruzada con otras fuentes de información sobre recursos naturales, distintas actividades humanas, datos sobre cambio climático y otros aspectos necesarios para intentar armonizar el desarrollo socioeconómico del estado con la conservación de su biota nativa.

Queda mucho por avanzar hacia un conocimiento suficiente de la mastofauna estatal en forma que realmente permita la planeación de su conservación y uso sustentable.

Esencialmente se requiere iniciar trabajos de campo en aquellas regiones que aún no han sido muestreadas, además de buscar mayor representatividad del muestreo para aquellas que ya cuentan con algunos registros. Aprovechando futuros muestreos es deseable que se tomen muestras que permitan estudios de genética molecular, y de incidencia de patógenos relacionados con enfermedades emergentes, sobre todo en sitios donde las actividades humanas están invadiendo tierras silvestres (Sánchez et al. 2012).

La detección de extensiones silvestres adicionales susceptibles de conservación en Guanajuato (como señalaron Botello et al. 2012) y la ampliación de programas y mejoramiento del manejo de las actuales ANP, como ha propuesto Guzmán González (2012), sin duda beneficiará a los mamíferos silvestres del estado.

También resulta recomendable estudiar los tipos y magnitudes de uso que se dan a los mamíferos silvestres, sea bajo esquemas regulados como las Unidades de Manejo para la Conservación de Vida Silvestre (UMA) o en situaciones ilícitas como la captura y caza furtivas.

Finalmente, para proteger la mastofauna nativa de Guanajuato es necesario mantener vigilancia respecto a la introducción, establecimiento y dispersión de especies exóticas invasoras como las ratas y ratones domésticos (Rattus rattus, R. norvegicus, Mus 
musculus), gatos (Felis sylvestris) y cabras (Capra hircus) entre otras, para no mencionar el omnipresente ganado vacuno, sobre todo en relación con las actuales ANP. Donde ya se les haya detectado, deben ser erradicadas lo antes posible, para evitar situaciones que comprometan a especies y ambientes nativos, como señalan Álvarez Romero et al. (2008) y Sánchez et al. (2012).

Este trabajo está dedicado a la memoria de Alfred Auguste Delsescautz Dugès, pionero de la investigación sobre la vida silvestre de Guanajuato en el Siglo XIX.

Es una grata obligación agradecer al personal curatorial de las colecciones mencionadas Agradecimientos en el Anexo I, cuyo esfuerzo por mantener al día las bases de datos físicas y en línea, y su generosa apertura a consultas a través de varios años, han permitido elucidar numerosos temas relativos a los mamíferos de Guanajuato: J. P. Dumbacher (CAS); F. A. Cervantes y Y. Hortelano (CNMA); F. Botello (IBUNAM: FCB); J. C. López-Vidal y C. ElizaldeArellano (ENCB-IPN); L. Heaney (FMNH); R. Timm (KU); J. Dines (LACM); G. MagañaCota (MADUG-MA); H. E. Hoekstra y J. M. Chupasko (MCZ); J. C. Hafner (MLZ-OC); S. Jansa $(M M N H)$; J. E. Light (TCWC); H. Garner (TTU); P. Myers, P. Tucker y B. Lundrigan (UMMZ); y M. D. Carleton, R. W. Thorington, Jr., K. M. Helgen y C. A. Ludwig (USNM).

Se reconoce especialmente la colaboración de J. Light (TCWC) y F. B. Stangl, Jr. (MSU) en la revisión de material altamente controversial de Sigmodon de Guanajuato.

El autor también expresa su reconocimiento a las atinadas observaciones de G. Magaña-Cota, de S. T. Álvarez-Castañeda, de G. Sánchez Rojas y de dos revisores anónimos, las cuales permitieron mejorar el manuscrito original.

Almanza Carrillo, R., y L. E. Juárez. 2012. El deterioro ambiental durante la fase inicial de poblamiento. Pp. 91-94 en La Biodiversidad en Guanajuato: Estudio de Estado vol. I. México, Comisión Nacional para el Conocimiento y Uso de la Biodiversidad (CONABIO)/Instituto de Ecología del Estado de Guanajuato (IEE). Ciudad de México, México.

Átvarez, T., y A. Ocaña. 1999. Sinopsis de los restos arqueozoológicos de vertebrados terrestres, basada en informes del Laboratorio de Paleozoología del INAH. Instituto Nacional de Antropología e Historia, Colección Científica 386:1-108.

Átvarez Castañeda, S. T. 2010. Phylogenetic structure of the Thomomys bottae-umbrinus complex in North America. Molecular Phylogenetics and Evolution 54:671-679.

Álvarez-Castañeda, S. T., I. Castro-Arellano, T. Lacher, y E. Vázquez. 2008. Dipodomys phillipsii. En: IUCN 2012. IUCN Red List of Threatened Species. Versión 2012.2. $<$ www.iucnredlist.org $>$. Descargado el 29 de enero 2013.

Álvarez-Romero, J. G., R. A. Medellín, A. Oliveras de Ita, H. Gómez de Silva, y O. Sánchez. 2008. Animales exóticos en México: una amenaza para la biodiversidad. Comisión Nacional para el Conocimiento y Uso de la Biodiversidad; Instituto de Ecología, Universidad Nacional Autónoma de México; Secretaría de Medio Ambiente y Recursos Naturales, Ciudad de México, México.

Andersen, J. J., y J. E. Light. 2012. Phylogeography and subspecies revision of the hispid pocket mouse, Chaetodipus hispidus (Rodentia: Heteromyidae). Journal of Mammalogy 93:1195-1215. 
Andersen, J. J., M. A. Renshaw, Y J. E. Light. 2012. Eight novel polymorphic microsatellites in the hispid pocket mouse (Chaetodipus hispidus) and cross-amplification in other Perognathinae species (Rodentia: Heteromyidae). http://link.springer.com/ journal/12686 4:1019-1021.

Apátiga, M. C., J. Boizo, y N. Mendoza. 2008. Mastofauna de la Sierra de los Agustinos. Pp. 97-109 en Diagnóstico ambiental del área de uso sustentable Sierra de los Agustinos, municipio de Acámbaro, Guanajuato (Villaseñor, L. E., ed.). Ayuntamiento de Acámbaro y Facultad de Biología de la Universidad Michoacana de San Nicolás de Hidalgo. Editorial Universitaria. Morelia, México.

Arita, H., Y D. Wilson. 1987. Long-Nosed Bats and the Agaves: The Tequila Connection. Bat Conservation International 5: 3-5.

Arroyo-Quiroz, I. y R. Perez-Gil. 2007. Human-Wildlife Interactions in the Sierra Gorda Biosphere Reserve, Mexico: Annual Report Y2. Rufford Foundation-Faunam, A. C. Ciudad de México, México.

BaKeR, R. H. 1969. Cotton rats of the Sigmodon fulviventer group. University of Kansas, Museum of Natural History, Miscellaneous Publications 51:177-232.

Bataillon, C. 1988. Las regiones geográficas de México. Siglo XXI Editores. Ciudad de México, México.

Best, T. L., y M. P. SкuPSKı. 1994. Perognathus flavus. Mammalian Species 471:1-10.

Botello, F., V. Sánchez-Cordero, G. E. Magaña-Cota, R. Cecaira-Ricoy, y E. Kato Miranda. 2012. Prioridades e instrumentos de conservación en el estado de Guanajuato. Pp. 406-412 en La Biodiversidad en Guanajuato: Estudio de Estado. Comisión Nacional para el Conocimiento y Uso de la Biodiversidad (CONABIO)/Instituto de Ecología del Estado de Guanajuato (IEE). Ciudad de México, México.

Brown, J. H., y C. F. Welser. 1968. Serum albumin polymorphisms in natural and laboratory populations of Peromyscus. Journal of Mammalogy 49:420-426.

Carleton, M. D., y J. Arroyo-Cabrales. 2009. Review of the Oryzomys couesi Complex (Rodentia: Cricetidae: Sigmodontinae) in Western Mexico. Bulletin of the American Museum of Natural History 331:94-127.

Carroll, D. S., y R. D. Bradley. 2005. Systematics of the genus Sigmodon: DNA sequences from beta-fibrinogen and cytochrome b. Southwestern Naturalist 50:342-349.

Carroll, D. S., L. L. Peppers, y R. D. Bradley. 2005. Molecular systematics and phylogeography of the Sigmodon hispidus species group. Pp. 87-100 en Contribuciones Mastozoológicas en Homenaje a Bernardo Villa (Sánchez-Cordero, V., y R. A. Medellín, eds). CONABIO, México: Instituto de Biología e Instituto de Ecología, UNAM. Ciudad de México, México.

Ceballos, G., J. Arroyo-Cabrales, R. A. Medellín, y Y. Domínguez-Castellanos. 2005. Lista actualizada de los mamíferos de México. Revista Mexicana de Mastozoología 9:21-71.

Ceballos, G., S. Blanco, C. González, y E. Martínez. 2006. Mapa: Antilocapra americana (berrendo). Distribución potencial escala1:1'000,000. Instituto de Ecología, Universidad Nacional Autónoma de México-CONABIO. http://www.conabio.gob. $\mathrm{mx} /$ informacion/gis/layouts/antamerigw.png

Ceballos, G., P. Manzano, F. M. Méndez-Harclerode, M. L. Haynie, D. H. Walker, y R. D. Bradley. 2010. Geographic Distribution, Genetic Diversity, and Conservation 
Status of the Southern Flying Squirrel (Glaucomys volans) in México. Occasional Papers of The Museum, Texas Tech University 299:2-15.

Ceballos, G., y J. Arroyo-Cabrales. 2012. Lista actualizada de los Mamíferos de México 2012. Revista Mexicana de Mastozoología, Nueva Época 2:27-80.

Cecaira-Ricoy, R., J. A. Iglesias-Hernández, J. F. Charre-Medellín, R. Bolaños M., G. E. Magaña-Cota, V. Sánchez-Cordero, E. Kato M., y F. J. Botello L. 2012. Registro notable de tres especies de mamíferos en la Reserva de la Biosfera Sierra Gorda de Guanajuato. Pp. 280-282 en La Biodiversidad en Guanajuato: Estudio de Estado vol. II. México. Comisión Nacional para el Conocimiento y Uso de la Biodiversidad (CONABIO)/Instituto de Ecología del Estado de Guanajuato (IEE). Ciudad de México, México.

Charre-Medeluin, J. F., C. López-González, A. Lozano, y A. F. Guzmán. 2011. Conocimiento actual sobre la nutria neotropical (Lontra longicaudis annectens) en el estado de Durango, México. Revista Mexicana de Biodiversidad 82:1343-1347.

Charre-Medellín, J. F., V. Sánchez-Cordero, G. Magaña-Cota, M. Álvarez-Jara, y F. Botello. 2012a. Jaguarundi (Puma yagouaroundi) in Guanajuato, Mexico. The Southwestern Naturalist 57:117-118.

Charre-Medellín, J. F., V. Sánchez-Cordero, G. E. Magaña-Cota, y F. J. Botello. 2012b. Estudio de la diversidad de mamíferos de talla mediana y grande del Municipio de Victoria. Pp. 277-279 en La Biodiversidad en Guanajuato: Estudio de Estado vol. II. México, Comisión Nacional para el Conocimiento y Uso de la Biodiversidad CONABIO)/Instituto de Ecología del Estado de Guanajuato (IEE). Ciudad de México, México.

CITES. 2012. Convención sobre el Comercio Internacional de Especies Amenazadas de Fauna y Flora Silvestres. Apéndices I, II y III en vigor a partir del 25 de septiembre de 2012. http://www.cites.org/esp/app/appendices.php.

Clavijero, F. X. 1780. Historia Antigua de México. (Edición 1964). Editorial Porrúa. Ciudad de México, México.

Cole, F. R., y D. E. Wiıson. 2006. Leptonycteris yerbabuenae. Mammalian Species 797:1-7.

CONABIO. 2012. Proyecto de Evaluación de las Unidades de Manejo para la Conservación de la Vida Silvestre (UMA) (1997-2008). Resultados de la Fase I: Gestión y Administración. Proyectos CONABIO: HV003, HV004, HV007, HV012 y HV019 (Sánchez, Ó., W. Medina., L. A. Antaño, G. López-Segurajáuregui, A. García-Naranjo y H. Benítez, comps.). Ciudad de México, México. http://www. biodiversidad.gob.mx/usos/UMAs.html

CONANP. 2013. Anteproyecto de Programa de Manejo de la Reserva de la Biosfera Sierra Gorda de Guanajuato (23/10/2013). http://www.conanp.gob.mx/acciones/ consulta/ Html consultada el 25 de marzo de 2014.

Cuevas Carrillo, J. I., y M. Zorrilla. 2012. Localización y superficie. Pp. 28-37 en La Biodiversidad en Guanajuato: Estudio de Estado vol. II. México, Comisión Nacional para el Conocimiento y Uso de la Biodiversidad CONABIO)/Instituto de Ecología del Estado de Guanajuato (IEE). Ciudad de México, México.

Dalquest, W. W. 1950. Records of mammals from the Mexican state of San Luis Potosi. Occasional Papers of the Museum of Zoology 23:1-15. 
DGVS-SEMARNAT. 2010. Plan de manejo tipo de Liebres y Conejos. Dirección General de Vida Silvestre-SEMARNAT. Ciudad de México, México.

Dugès, A. A. D. 1870. Catálogo de animales vertebrados observados en la República Mexicana. La Naturaleza, primera serie 1:137-145.

Dugès, A. A. D. 1874. El tlalcoyotl, por el Sr. don Alfredo Dugès, socio corresponsal en Guanajuato. La Naturaleza 3 (año 1876):156-159.

Dugès, A. A. D. 1890. Fauna del estado de Guanajuato. Pp. 287-295 en Geografía y Estadística del estado de Guanajuato (Velasco, A. L.). Oficina Tipográfica de la Secretaría de Fomento. Ciudad de México, México.

Dugès, A. A. D. 1895 . Fauna del Estado de Guanajuato. En Memoria sobre la administración pública del Estado de Guanajuato presentada al Congreso del mismo por el C. Gobernador Constitucional Lic. Joaquín Obregón González, el 1 de abril de 1895 (8 pp.). Imprenta y Litografía de la Escuela IM Porfirio Díaz. Morelia, Michoacán.

Dugès, A. A. D. 1908. Dipodomys phillipsi Gray. Memorias de la Sociedad Científica Antonio Alzate 26:407-411.

Edwards, C. W., C. F. Fulhorst, y R. D. Bradley. 2001. Molecular phylogenetics of the Neotoma albigula species group: further evidence of a paraphyletic assemblage. Journal of Mammalogy 82:267-279.

Elizalde-Arellano, C., J. C. López-Vidal, E. Q. Uhart, J. I. Campos-Rodríguez, y R. HernándezArciga. 2010. Nuevos registros y extensiones de distribución de mamíferos para Guanajuato, México. Acta Zoológica Mexicana (n. s.) 26:73-98.

Fernández, J. A., F. A. Cervantes, y M. S. Hafner. 2012. Molecular systematics and biogeography of the Mexican endemic kangaroo rat, Dipodomys phillipsii (Rodentia: Heteromyidae). Journal of Mammalogy 93:560-571.

Gallina-Tessaro, S. A., A. Hernández-Huerta, C. A. Delfín-Alfonso, y A. González-Galuina. 2009. Unidades para la conservación, manejo y aprovechamiento sustentable de la vida silvestre en México (UMA). Retos para su correcto funcionamiento. Investigación Ambiental 1:143-152.

Gallo, J. P. 1997. Situación y distribución de las nutrias en México, con énfasis en Lontra longicaudis annectens Major, 1897. Revista Mexicana de Mastozoología 2:10-32.

García, N. H., D. R. R. García, S. R. Moreno, y R. A. González. 2002. Uso de sensores remotos y SIG para delimitar los cambios en el uso del suelo agrícola de 19701997 en Guanajuato. Boletín del Instituto de Geografía, Universidad Nacional Autónoma de México 47:92-112.

Genoways, H. H., Y J. K. Jones. 1971. Systematics of southern banner-tailed kangaroo rats of the Dipodomys phillipsii group. Journal of Mammalogy 52:265-287.

Genoways, H. H., Y J. K. Jones. 1973. Notes on some mammals from Jalisco, Mexico. Occasional Papers of The Museum, Texas Tech University 9:1-22.

Godinez-Alvarez, H., y A. Valiente-Banuet. 2000. Fruit-Feeding Behavior of the Bats Leptonycteris curasoae and Choeronycteris mexicana in Flight Cage Experiments: Consequences for Dispersal of Columnar Cactus Seeds. Biotropica 32:552-556. 
Guzmán González, D. 2012. Las Áreas Naturales Protegidas del estado de Guanajuato y su importancia en la conservación de la biodiversidad. Pp. 373-388 en La Biodiversidad en Guanajuato: Estudio de Estado. Comisión Nacional para el Conocimiento y Uso de la Biodiversidad (CONABIO)/Instituto de Ecología del Estado de Guanajuato (IEE). Ciudad de México, México.

Hafner, M. S., T. A. Sprading, J. E. Light, D. J. Hafner, y J. R. Demboski. 2004. Systematic revision of pocket gophers of the Cratogeomys gymnurus species group. Journal of Mammalogy 85:1170-1183.

Hafner, J., C., J. E. Light, D. J. hafner, M. S. Hafner, E. Reddington, D. S. Rogers, y B. R. RidDLE. 2007. Basal clades and molecular systematics of heteromyid rodents. Journal of Mammalogy 88:1129-1145.

HaLL, E. R. 1981. The Mammals of North America. John Wiley and Sons. New York, EE.UU.

Hall, E. R., Y K. H. Kelson. 1959. The Mammals of North America (vol. 1). The Ronald Press Co. New York, EE.UU.

Helgen, K. M., F. R. Cole, L. E. Helgen, y D. E. Wilson. 2009. Generic revision in the Holarctic ground squirrel genus Spermophilus. Journal of Mammalogy 90:270305.

Henson, D. D., y R. D. Bradley. 2009. Molecular systematics of the genus Sigmodon: results from mitochondrial and nuclear gene sequences. Canadian Journal of Zoology 87:211-220.

Homan, J. A., Y H. H. Genoways. 1978. An analysis of hair structure and its phylogenetic implications among heteromyid rodents. Journal of Mammalogy 59:740-760.

Hoofer, S. R., Y R. A. Van Den Bussche. 2001. Phylogenetic relationships of plecotine bats and allies based on mitochondrial ribosomal sequences. Journal of Mammalogy 82:131-137.

Hoofer, S. R., y R. A. Van Den Bussche. 2003. Molecular phylogenetics of the chiropteran family Vespertilionidae. Acta Chiropterologica 5:1-63.

Howel, A. H. 1938. Revision of the North American ground squirrels, with a classification of the North American Sciuridae. North American Fauna 56:1-256.

IEE. 2009. Sistema de Monitoreo Ambiental de los Recursos Naturales del Estado de Guanajuato. Síntesis de resultados 1970-2004. Ordenamiento Ecológico del Territorio del Estado de Guanajuato. Instituto de Ecología del Estado de Guanajuato. Ciudad de Guanajuato, México.

IEE. 2013. Áreas Naturales Protegidas del estado de Guanajuato. Instituto de Ecología del Estado de Guanajuato. http://ecologia.guanajuato.gob.mx/sitio/areas-naturalesprotegidas\#areas-naturales-protegidas-anps. Consultado el 25 de marzo de 2014.

Iglesias, J. A., V. Sánchez-Cordero, G. E. Magaña-Cota, R. Bolaños, M. Aranda, R. Hernández, y F. J. Botello. 2008. Noteworthy records of margay, Leopardus wiedii and ocelot, Leopardus pardalis in the state of Guanajuato, Mexico. Mammalia 72:347-349.

Iglesias, J. A., V. Sánchez-Cordero, G. E. Magaña-Cota, R. Bolaños Martínez, y F. J. Botello LóPEz. 2012. Diversidad de mamíferos medianos y grandes en el Municipio de Xichú. Pp. 275-276 en La Biodiversidad en Guanajuato: Estudio de Estado vol. II. 
Comisión Nacional para el Conocimiento y Uso de la Biodiversidad (CONABIO)/ Instituto de Ecología del Estado de Guanajuato (IEE). Ciudad de México, México.

INEGI. 2005. Marco geoestadístico municipal. Instituto Nacional de Estadística y Geografía. Ciudad de México, México.

INEGI. 2011. Panorama sociodemográfico de México. Instituto Nacional de Estadística y Geografía. Ciudad de México, México.

Íñ IGueZ, L. I., y E. SANtana. 2005. Análisis mastofaunístico del estado de Jalisco. Pp. 253268 en Contribuciones Mastozoológicas en Homenaje a Bernardo Villa (SánchezCordero, V., y R. A. Medellín eds.). Instituto de Biología, Instituto de Ecología y Comisión Nacional para el Conocimiento y Uso de la Biodiversidad. Ciudad de México, México.

IUCN. 2012. The IUCN Red List of Threatened Species 2012.2. International Union for The Conservation of Nature. http;//www.iucnredlist.org

IUDiCA, C. A. 2000. Systematic revision of the Neotropical fruit bats of the genus Sturnira: a molecular and morphological approach. Department of Zoology, University of Florida. Gainesville, Florida.

JaCkson, S. M. 2012. Gliding mammals of the world (illustrated by Peter Schouten). xi + 215 pp . CSIRO Publishing. Collingwood, Australia.

Jour, P. L. 1893. Notes on birds of central Mexico, with descriptions of forms believed to be new. Proceedings of the U. S. National Museum 16:771-791.

Juárez, L. E. 2012. Perspectiva histórica de la conformación y el uso del territorio: Siglo XVI al XIX. Pp. 95-99 en La Biodiversidad en Guanajuato: Estudio de Estado. México, Comisión Nacional para el Conocimiento y Uso de la Biodiversidad (CONABIO)/Instituto de Ecología del Estado de Guanajuato (IEE). Ciudad de México, México.

Kellert, S. R. 1985. Social and perceptual factors in endangered species management. Journal of Wildlife Management 49:528-536

Linzey, A. V., R. Timm, S. T. Álvarez-Castañeda, I. Castro-Arellano, y T. Lacher. 2008. Sigmodon ochrognathus. IUCN 2012. IUCN Red List of Threatened Species. Versión 2012.2. <www.iucnredlist.org>. Descargado el 20 de enero, 2013.

López-González, C., y L. Torres-Morales. 2004. Use of abandoned mines by long-eared bats, genus Corynorhinus (Chiroptera: Vespertilionidae) in Durango, Mexico. Journal of Mammalogy 85:989-994.

LóPez-Wiıchis, R. 1989. Biología de Plecotus mexicanus (Chiroptera: Vespertilionidae) en el estado de Tlaxcala, México. Tesis Doctoral, Facultad de Ciencias, Universidad Nacional Autónoma de México. Ciudad de México, México.

Lozoya Gloria, E., y P. Uriarte Garzón. 2012. Fauna del Área Natural Protegida Cerro de Arandas, Irapuato. Pp. 395-405 en La Biodiversidad en Guanajuato: Estudio de Estado. México, Comisión Nacional para el Conocimiento y Uso de la Biodiversidad (CONABIO)/Instituto de Ecología del Estado de Guanajuato (IEE). Ciudad de México, México.

Magaña-Cota, G. E. (COORd.). 2008. Alfredo Dugès: Notas de zoología tomadas durante mi estancia en México, Cuaderno 2. Universidad de Guanajuato. Guanajuato, México. 
Magaña-Cota, G. E., J. F. Charre-Medellín, R. Hernández, J. Iglesias, Belén Chávez-Gaiván, R. Bolaños, R. Cecaira-Ricoy, V. Sánchez-Cordero, y F. Botello. 2010. Primeros registros del murciélago vampiro de pata peluda (Diphylla ecaudata) para el estado de Guanajuato, México. Therya 1:213-220.

Magaña-Cota, G. E., F. Botello, J. Iglesias-Hernández, M. E. Portillo-Vega, y V. SánchezCordero. 2012. Riqueza específica de roedores en el estado de Guanajuato, México. Pp. 247-265 en Estudios sobre la Biología de Roedores Silvestres Mexicanos (Cervantes, F. A., y C. Ballesteros-Barrera, eds.). Universidad Nacional Autónoma de México y Universidad Autónoma Metropolitana. Ciudad de México, México.

Mandujano, S., C. A. Delfín-Alfonso, y S. Galuina. 2010. Comparison of geographic distribution models of white-tailed deer Odocoileus virginianus (Zimmermann, 1780) subspecies in Mexico: biological and management implications. Therya 1:41-68.

Mattern, M. Y. y D. A. McLennan. 2000. Phylogeny and Speciation of Felids. Cladistics 16:232-253.

Miller, B., R. Reading, J. Stritthold, C. Carroll, R. Noss, M. Soulé, O. Sánchez, J. Terborgh, D. Brightsmith, T. Cheeseman y D. Foreman. 1999. Using focal species in the design of nature reserve networks. Wild Earth 1999:81-92.

Monroy-Vilchis, O., y V. Mundo. 2009. Nicho trófico de la nutria neotropical (Lontra longicaudis) en un ambiente modificado, Temascaltepec, México. Revista Mexicana de Biodiversidad 80:801-806.

Nelson, E. W. 1909. The rabbits of North America. North American Fauna 29:1-314.

NúÑEz-Garduño, A. 2005. Los mamíferos silvestres de Michoacán, diversidad, biología e importancia. 452 pp. Universidad Michoacana de San Nicolás de Hidalgo/ Secretaria de Difusión Cultural y Extensión Universitaria. Morelia, México.

Oscood, W. H. 1909. Revision of the mice of the American genus Peromyscus. North American Fauna 28:1-267.

Paredes Melesio, R., A. Mandujano Bueno, A. J. Gámez Vázquez, y H. García Nieto. 2011. Actualización del mapa de uso del suelo agrícola en el estado de Guanajuato. Revista Mexicana de Ciencias Agrícolas 2:85-96.

Peppers, L. L., y R. D. Bradley. 2000. Cryptic speciation in Sigmodon hispidus: evidence from DNA sequences. Journal of Mammalogy 81:332-343.

Peppers, L. L., D. S. Carroll, y R. D. Bradley. 2002. Molecular systematics of the genus Sigmodon (Rodentia: Muridae): evidence from the mitochondrial cytochrome b gene. Journal of Mammalogy 83:396-407.

Pineda, A. 1978. La vegetación forestal en el estado de Guanajuato. Bosques y Fauna 1:31-88.

Ramírez-Pulido, J., J. Arroyo-Cabrales, y A. Castro-Campillo. 2005. Estado actual y relación nomenclatural de los mamíferos terrestres de México. Acta Zoológica Mexicana (n. s.) 21:21-82.

Roehrs, Z, P., J. B. Lack, y R. A. Van Den Bussche. 2010. Tribal phylogenetic relationships within Vespertilioninae (Chiroptera: Vespertilionidae) based on mitochondrial and nuclear sequence data. Journal of Mammalogy 91:1073-1092. 
Sánchez, Ó., R. A. Medellín, A. Aldama, B. Goettsch, J. Soberón, y M. Tambutti. 2007. Método de evaluación del riesgo de extinción de las especies silvestres en México (MER).Secretaría de Medio Ambiente y Recursos Naturales, Instituto Nacional de Ecología, Instituto de Ecología de la Universidad Nacional Autónoma de México y Comisión Nacional para el Conocimiento y Uso de la Biodiversidad. Ciudad de México, México.

Sánchez, Ó., y G. E. Magaña-Cota. 2008. Murciélagos de Guanajuato: Perspectiva histórica y actualización de su conocimiento. Acta Universitaria 18:27-39.

Sánchez, Ó., G. Téllez-Girón, y G. Magaña-Cota. 2009. Registros adicionales de murciélagos para Guanajuato. Acta Universitaria 19:40-47.

Sánchez, Ó., C. Elizalde-Arellano, J. C. López-Vidal, G. Magaña-Cota, G. Téllez-Girón, F. Botello, y V. Sánchez-Cordero. 2012. Mamíferos silvestres. Pp. 263-274 en La Biodiversidad en Guanajuato: Estudio de Estado vol. II. México, Comisión Nacional para el Conocimiento y Uso de la Biodiversidad (CONABIO)/Instituto de Ecología del Estado de Guanajuato (IEE). Ciudad de México, México.

Sánchez, Ó., G. E. Magaña-Cota, G. Téllez-Girón, W. López-Forment, y G. Urbano-Vidales. 2014. Mamíferos no voladores de Guanajuato, México: revisión histórica y lista taxonómica actualizada. Acta Universitaria 24:3-37.

Sánchez-Cordero, V., F. Botello, G. Magaña-Cota, y J. Iglesias. 2011. Vampire bats, Desmodus rotundus, feeding on white-tailed deer, Odocoileus virginianus. Mammalia 75:91-92.

Segura, V., F. Prevosti, y G. Cassini. 2013. Cranial ontogeny in the Puma lineage, Puma concolor, Herpailurus yagouaroundi, and Acinonyx jubatus (Carnivora, Felidae): a three-dimensional geometric morphometric approach. Zoological Journal of the Linnean Society 169:235-250.

SEMARNAT. 2010. Norma Oficial Mexicana NOM-059-SEMARNAT-2010, Protección ambiental-Especies nativas de México de flora y fauna silvestres-Categorías de riesgo y especificaciones para su inclusión, exclusión o cambio-Lista de especies en riesgo. Diario Oficial de la Federación, 30/12/2010. Ciudad de México, México. http://dof.gob.mx/nota_detalle.php?codigo=5173091\&fecha=30/12/2010

SEMARNAT. 2014. ACUERDO por el que se da a conocer la lista de especies y poblaciones prioritarias para la conservación. Diario Oficial de la Federación, 05/03/2014. Ciudad de México, México.

Simmons, N. B. 1998. Order Chiroptera. Pp. 312-529 en Mammal Species of the World: a taxonomic and geographic reference (Wilson, D. E.,y Reeder, D. M. eds.). 3rd ed. The Johns Hopkins University Press. Baltimore EE.UU.

Simmons, N. B., y A. L. Wetterer. 2002. Convergence and phylogeny of cactophilic bats. Pp. 87-121 en Evolution, Ecology, and Conservation of Columnar Cacti and their Mutualists (Fleming, T., y A. Valiente-Banuet, eds.). University of Arizona Press. Tucson, EE.UU.

Steppan, S. J., R. M. Adkins, y J. Anderson. 2004. Phylogeny and divergence-date estimates of rapid radiations in muroid rodents based on multiple nuclear genes. Systematic Biology 53:533-553. 
Thorington, R. W., JR., y R. S. Hoffmann. 2005. Sciurus (Sciurus) aureogaster. Pp. 754-818 en Mammal Species of the World: a taxonomic and geographic reference (Wilson, D. E., y D. M. Reeder, eds.). Tercera edición. The Johns Hopkins University Press. Baltimore, EE.UU.

Torquemada (DE), J. 1615. Los veintiún libros rituales i monarchia Indiana con el origen y guerras de los Indios Occidentales, de sus poblaciones, descubrimientos, conquista, conversión y otras cosas maravillosas de la misma tierra. En 3 Volúmenes, reimpreso en 1723 por Nicolás Rodríguez Franco. Madrid, España.

Uriarte-Garzón, P., y E. Lozoya Gloria. 2009. Manual del inventario de la fauna del área natural protegida "Cerro de Arandas", Irapuato, Guanajuato. Parque Ecológico de Irapuato, A. C., CONCyTEG, CONACyT y CINVESTAV. Irapuato, México.

Valiente-Banuet, A., M. C. Arizmendi, A. Rojas-Martínez, y L. Domínguez-Canseco. 1996. Ecological relationships between columnar cacti and nectar-feeding bats in Mexico. Journal of Tropical Ecology 12:103-119.

Velazco, P. M., y B. D. Patterson. 2013. Diversification of the Yellow-shouldered bats, Genus Sturnira (Chiroptera, Phyllostomidae), in the New World tropics. Molecular Phylogenetics and Evolution 68:683-698.

Wilson, D. E., y D. A. M. Reeder (eds.). 2005. Mammal Species of the World. A Taxonomic and Geographic Reference. Tercera edición. Johns Hopkins University Press. Baltimore, EE.UU.

Zamudio Ruiz, S. 2012. Diversidad de ecosistemas del estado de Guanajuato: regionalización ecológica. Pp. 21-55 en La Biodiversidad en Guanajuato: Estudio de Estado vol. II. México, Comisión Nacional para el Conocimiento y Uso de la Biodiversidad (CONABIO)/Instituto de Ecología del Estado de Guanajuato (IEE). Ciudad de México, México.

ZimmermanN, E. G. 1970. Karyology, systematics and chromosomal evolution in the rodent genus Sigmodon. Publications of the Museum, Michigan State University, Biological Series 4:385-454.

Sometido: 20 de enero de 2014

Revisado: 15 de marzo de 2014

Aceptado: 20 de abril de 2014

Editor asociado: Sergio Ticul Álvarez-Castañeda

Diseño gráfico editorial: Gerardo Hernández 


\section{Apéndice I}

\section{Acrónimos de los museos mencionados en el texto}

CAS. California Academy of Sciences.

CNMA. Colección Nacional de Mamíferos, Instituto de Biología, Universidad Nacional Autónoma de México (F. A. Cervantes, Y. Hortelano).

ENCB-IPN. Colección de Mamíferos, Escuela Nacional de Ciencias Biológicas, Instituto Politécnico Nacional, México.

FMNH. Field Museum of Natural History.

IBUNAM:CFB. Colección de Fotocolectas Biológicas, Instituto de Biología, Universidad Nacional Autónoma de México (F. Botello).

KU. University of Kansas Natural History Museum.

LACM. Natural History Museum of Los Angeles County.

MADUG-MA. Museo de Historia Natural "Alfredo Dugès", Universidad de Guanajuato. MCZ. Harvard University, Museum of Comparative Zoology.

MLZ-OC. Moore Laboratory of Zoology, Occidental College.

MMNH. Bell Museum of Natural History, University of Minnesota.

MSU. Midwestern State University, Wichita Falls, Texas.

TCWC. Texas A\&M University, Texas Cooperative Wildlife Collection.

TTU. Museum of Texas Tech University.

UMMZ. University of Michigan, Museum of Zoology.

USNM. National Museum of Natural History, Washington. 
